\title{
MicroRNA and Transcription Factor: Key Players in Plant Regulatory Network
}

\author{
Abdul F. A. Samad', Muhammad Sajad 2,3, Nazaruddin Nazaruddin'1,4, Izzat A. Fauzi', \\ Abdul M. A. Murad' ${ }^{1}$, Zamri Zainal ${ }^{1,3}$ and Ismanizan Ismail1,3*
}

${ }^{1}$ School of Biosciences and Biotechnology, Faculty of Science and Technology, National University of Malaysia, Selangor, Malaysia, ${ }^{2}$ Department of Plant Breeding and Genetics, University College of Agriculture and Environmental Sciences, The Islamia University of Bahawalpur, Punjab, Pakistan, ${ }^{3}$ Centre of Plant Biotechnology, Institute of Systems Biology, National University of Malaysia, Selangor, Malaysia, ${ }^{4}$ Department of Chemistry, Faculty of Mathematics and Natural Sciences, Syiah Kuala University, Darussalam, Banda Aceh, Indonesia

\section{OPEN ACCESS}

Edited by:

Agnieszka Ludwików, Adam Mickiewicz University

in Poznań, Poland

Reviewed by: Agnieszka Kietbowicz-Matuk, Polish Academy of Sciences (PAN),

Poland

Sailendra Nath Sarkar, University of Calcutta, India

*Correspondence: Ismanizan Ismail maniz@ukm.edu.my

Specialty section: This article was submitted to Plant Biotechnology, a section of the journal Frontiers in Plant Science

Received: 13 January 2017 Accepted: 29 March 2017

Published: 12 April 2017

Citation:

Samad AFA, Sajad M, Nazaruddin N,

Fauzi IA, Murad AMA, Zainal Z and Ismail I (2017)

MicroRNA and Transcription Factor: Key Players in Plant Regulatory Network. Front. Plant Sci. 8:565. doi: 10.3389/fpls.2017.00565
Recent achievements in plant microRNA (miRNA), a large class of small and non-coding RNAs, are very exciting. A wide array of techniques involving forward genetic, molecular cloning, bioinformatic analysis, and the latest technology, deep sequencing have greatly advanced miRNA discovery. A tiny miRNA sequence has the ability to target single/multiple mRNA targets. Most of the miRNA targets are transcription factors (TFs) which have paramount importance in regulating the plant growth and development. Various families of TFs, which have regulated a range of regulatory networks, may assist plants to grow under normal and stress environmental conditions. This present review focuses on the regulatory relationships between miRNAs and different families of TFs like; NF-Y, MYB, AP2, TCP, WRKY, NAC, GRF, and SPL. For instance NF-Y play important role during drought tolerance and flower development, MYB are involved in signal transduction and biosynthesis of secondary metabolites, AP2 regulate the floral development and nodule formation, TCP direct leaf development and growth hormones signaling. WRKY have known roles in multiple stress tolerances, NAC regulate lateral root formation, GRF are involved in root growth, flower, and seed development, and SPL regulate plant transition from juvenile to adult. We also studied the relation between miRNAs and TFs by consolidating the research findings from different plant species which will help plant scientists in understanding the mechanism of action and interaction between these regulators in the plant growth and development under normal and stress environmental conditions.

Keywords: miRNAs, transcription factors, plant development, stress response, plant regulators

\section{INTRODUCTION}

The recent discovery of complex regulatory network in higher organisms like; plants and animals have been recognized in plants (Morris and Mattick, 2014). These complex networks which consist of chromatin modification (at epigenetic level), mRNA splicing, cell signaling, polyadenylation, and mechanisms of protein activation and degradation demanded substantial attention in order to achieve complete understanding on how plant system are being regulated (Boucas et al., 2012; Holoch and Moazed, 2015). This review has been intended to focus on gene regulation 
at transcriptional and post-transcriptional levels which involving microRNAs (miRNAs) and transcription factors (TFs) as key regulatory players.

At the transcriptional level, the interaction of TFs interact with enhancers to coordinate gene expression has been well established in the past decade (Yu and Gerstein, 2006; Osorio, 2016). This can be obviously seen in the discovery of many types of TFs families which play a diverse role in plant system (Duval et al., 2014). At the post-transcriptional level, another attractive mechanism of gene regulation has been discovered a couple of decades ago, involving a large class of small non-coding RNAs, known as miRNAs. These miRNAs act as gene regulators in plants and animals by negatively regulate mRNAs (Bartel, 2004; Thomson and Dinger, 2016). With the increasing number of regulators involved in gene networks, it is interesting to observe and understand a dynamic relationship between miRNAs, TFs, and mRNAs.

To date, about 28,645 miRNAs from plants, animals, and viruses have been registered in public miRNA database (Kozomara and Griffiths-Jones, 2014; Wang Y. et al., 2016). These miRNAs are able to modulate and fine-tune majority of biological processes by regulating a large number of target genes (Krol et al., 2010; Nazarov et al., 2013). Thus, screening of the potential target genes can provide an efficient and critical approach to explore the miRNA-mediated regulatory functions in depth at post-transcriptional level. Early exploration of some empirical parameters and algorithms deduced for known miRNA-target interactions using computational prediction in Arabidopsis had been applied to determine miRNA targets in other plants (Ahmed et al., 2013; Cammaerts et al., 2015). The prediction approaches have further been validated through wet lab techniques and methods like PAGE, Northern Blot, Rapid Amplification of cDNA Ends at $5^{\prime}$ (5'-RACE), and Degradome Sequencing analysis (Lv et al., 2010; Akhtar et al., 2015).

Currently there are 58 families of TFs which consist of 320,370 members from 165 plant species (Jin et al., 2017). miRNAs only downregulate their targets while TFs activate or repress the transcription of their targets, eventually determining the fate of particular gene, either to be switched "on" or switched "off" (Istrail et al., 2007; Chow et al., 2016). Interestingly, majority of miRNA targets are TFs (Rhoades et al., 2002; Mitsuda and Ohme-Takagi, 2009; Kamthan et al., 2015). Since both regulators demonstrate great impact toward plant genetic system, the circuiting of miRNAs-TFs will allow orchestration of numerous biological processes with high reliability.

Recent trends in miRNA research were focused on plant responses to abiotic rather than biotic stresses (Mittler, 2006; Zhang, 2015). The prevailing environmental stresses like; drought, salinity, and cold, which significantly affect plant growth and development, are the prominent factors of plant research shift toward abiotic stress. The present review will provide a better understanding of miRNAs regulation and their interaction with the TFs, which can assist the researchers to explore more about plant survival mechanism under unfavorable environmental conditions. The newly developed relationship among the above mentioned gene regulators will assist the plant scientists to gain insight into the relationship among these regulators in different plant species.

\section{MIRNA BIOGENESIS AND MODE OF ACTION IN PLANT}

In plants, miRNA genes are transcribed by RNA polymerase II to produce primary miRNA (Pri-miRNA) and their length is highly variable between themselves (Voinnet, 2009; Axtell et al., 2011; Chang et al., 2012; Ma et al., 2015). Unlike animal, plant miRNA processing is accomplished inside the nucleus because they lack protein processor like Drosha and DGCR8. In plant, DICER-LIKE 1 (DCL1) process most of pri-miRNAs by cleavage. Pri-miRNAs are stabilized with a type of RNA binding protein, DAWDLE (DDL), which interacts with DCL1 in nuclear foci, named dicing bodies (D-bodies). The combined action of couple of proteins like; SERRATE (SE) and HYPONASTIC LEAVES 1 (HYL1), followed by DCL1 and the nuclear cap-binding complex, led to form a short duplex miRNA which consist of mature miRNA guide cleavage and passenger miRNA strand (miRNA*) (Rogers and Chen, 2013; Ha and Kim, 2014; Baranauskè et al., 2015). Further processing of this duplex leds to the $2^{\prime}-O$ methylation at $3^{\prime}$ by the methyltransferase HEN1 (Rogers and Chen, 2013; Baranauske et al., 2015). A family of enzymes, called SMALL RNA DEGRADING NUCLEASE (SDN) genes, is responsible for the accumulation of miRNAs. SDN1 have shown $3^{\prime}-5^{\prime}$ exoribonuclease activity against short and single-stranded RNA substrates (Ramachandran and Chen, 2008; Baranauskè et al., 2015; Meyer et al., 2015). In plants, HASTY (HST), which is homolog to EXPORTIN5 (EXP5), plays a crucial role in exporting pre-miRNAs or mature miRNAs to cytoplasm (Rogers and Chen, 2013; Shriram et al., 2016). Another export pathway of miRNAs seems to be involved but the exact mechanism is still not clear (Rogers and Chen, 2013; Ha and Kim, 2014).

In the cytoplasm, ARGONAUTE (AGO) proteins form an assembly with miRNA, known as RNA-induced silencing complex (RISC) (Arribas-Hernández et al., 2016; Eckardt, 2016). AGO1 in the RISC is the major player for the miRNA pathway (Ha and Kim, 2014; Shao et al., 2014). AGO protein consist of PAZ and PIWI domain (Miyoshi et al., 2016). Particularly, PIWI domain form RNaseH-like fold which catalyze endonuclease activity. This endonuclease activity is capable of chopping RNA targets that are complementary to the miRNA strand loaded inside the AGO (Arribas-Hernández et al., 2016; Miyoshi et al., 2016). AGO proteins in Arabidopsis thaliana such as AGO1, AGO2, and AGO10 has been reported to have the endonuclease activity, which leds to splicing the mRNA targets (Ji et al., 2011; Maunoury and Vaucheret, 2011; Zhu et al., 2011). Identification of the sliced mRNA targets by miRNA can be discovered through sequencing of mRNA degradome (Yang et al., 2013; Mutum et al., 2016). Previous study reveals that plant miRNAs bind to their targets with high complementary which results in the cleavage of target mRNA (Fahlgren and Carrington, 2010; ArribasHernández et al., 2016). Beside of cleavage, there are several cases where the miRNA target is regulated at protein level without significant changes in mRNA level. These findings suggest that 
plant miRNAs are capable in interfering the translation process of mRNA (Beauclair et al., 2010; Li et al., 2013).

\section{TFs FOR GENE REGULATION IN PLANT}

Transcription factors are essential for the regulation of gene expression, and usually belong to members of multigene families (Salih et al., 2016). Generally TFs exist as modular proteins containing of DNA-binding domain that interacts with ciselements of their target genes (Boeva, 2016; Orenstein and Shamir, 2016). Besides, it also consists of protein-protein interaction domain that assists oligomerization between TFs or with other regulators (Padi and Quackenbush, 2015; Boeva, 2016). Many TFs have been recognized by X-ray crystallography and Nuclear Magnetic Resonance spectroscopy (Dantas Machado et al., 2014; Pecenova and Farkas, 2016). TFs families can be evolved in many ways such as exon capture, duplication, translocation and mutation (Edger and Pires, 2009; Sharma et al., 2013). In plants, the regulation of TFs genes occurs at transcriptional and post-transcriptional levels (Liu et al., 1999; Lelli et al., 2012; Payne and Wagner, 2015). They participate in genetic system via many ways such as developmental control, elicitation of defense, and stress responses by expressing the gene at right time and right place (Levine and Davidson, 2005; Shiu et al., 2005; Wang H. et al., 2016; Wong et al., 2016; Zhang et al., 2016).

Hence, understanding the activity of TFs expression is crucial for building regulatory networks. Mode of action of TFs is considered to occur mainly through the binding of TFs to cis-regulatory element within the promoter regions of their targets genes (Biłas et al., 2016). However, with various posttranscriptional regulatory mechanisms that recently have been discovered, including; miRNA regulation (Meng et al., 2011; Naeem et al., 2011; Gulyaeva and Kushlinskiy, 2016; Lai et al., 2016), nonsense-mediated mRNA decay (Chang et al., 2007; Brogna and Wen, 2009; Hug et al., 2016), and nuclear export control (Erkmann and Kutay, 2004; Wickramasinghe et al., 2014; Wickramasinghe and Laskey, 2015), it evidences that mRNAs are regulated at many layers of gene regulation. Undoubtedly, there is a potential for altering expression patterns mediated by cis-elements through post-transcriptional regulation. Beside, a single TF has the ability to regulate multiple genes in certain metabolic pathways (Hao et al., 2011; Pireyre and Burow, 2015). Further, it is also quite clear through recent investigations that changes in gene transcription are closely related to changes in the expression of TFs (Yan X. et al., 2013). Therefore, alteration in the expression of TF genes normally results in remarkable changes during plant growth and development (Li et al., 2015). As a future consequence, engineering of transcription factor genes may provide a valuable means for manipulation of desired traits in plants (Pandey et al., 2014; Weng et al., 2016). Here we have reviewed briefly TF families that involve in plant growth and development under normal and stress environmental condition.

NF-Y or also known as Nuclear factor Y, are TFs that consist of three subunits, NF-YA (CBF-B or HAP2), NF-YB (CBF-A or HAP3), and NF-YC (CBF-C or HAP5). All of these subunits are essential for DNA binding (Ren et al., 2016). NF-Y, in the promoter region, recognize CCAAT box with high specificity and affinity due to the presence of its highly conserved trimeric activator (Ly et al., 2013; Ren et al., 2016; Siriwardana et al., 2016). These transcription factors have different functions according to their subunits. For instances, NF-YA and NF-YB involve in drought tolerance and NF-YC, appears to be important regulator in flowering and photomorphogenesis (Petroni et al., 2012; Myers et al., 2016). Nf-y mutant plant exhibited dark grown phenotype, although in the present of light, thus indicate NFY TF were positive regulators of photomorphogenesis (Myers et al., 2016). NY-FA participated in flowering process when in complex with NF-YB/NF-YC by activating FLOWERING LOCUS $T$ gene (Siriwardana et al., 2016). Transgenic Arabidopsis plants overexpressing NFYA5 resulted to high drought tolerance (Li et al., 2008; Petroni et al., 2012).

MYB (myeloblastosis) is a large family of proteins, playing diverse role in gene network in eukaryotes. Most MYB proteins act as TFs with different numbers of MYB domain repeats; MYBrelated, R2R3-MYB, R1R2R3-MYB, and atypical MYB family which exhibited their ability to bind DNA (Ambawat et al., 2013; Wu et al., 2016). They are widely distributed in plants and also interact with other TFs (Liu et al., 2008; Ambawat et al., 2013; Nguyen and Lee, 2016). MYB have been involved in growth and development of different plant species, e.g., in Glycine max, they are involved in flower color development (Takahashi et al., 2013), and in signal transduction pathways in A. thaliana, Oryza sativa, and cassava (Raffaele et al., 2006; Bakhshi et al., 2016; Liao et al., 2016). In A. thaliana and Medicago truncatula they regulate the biosynthesis of secondary metabolites (Gonzalez et al., 2008; Verdier et al., 2012; Liu et al., 2015; Nguyen and Lee, 2016).

APETALA2 (AP2) family of TFs plays a pivotal role in regulating the complex developmental process of floral development (Liu et al., 2012). AP2 family, also called class "A" of TFs, interacts with other two classes (B and C) of TFs and determines the final development of the floral organs, and this interaction was summarized as ABC model (Bemis et al., 2013; Krizek and Anderson, 2013; Xie et al., 2015). Complexity of floral formation shown by co-regulation of three classes of TFs, class A, $\mathrm{B}$, and $\mathrm{C}$ genes, which determine the four floral organ types (Pelaz et al., 2000; Xie et al., 2015). Family of class A TFs (AP2) itself alone regulate the identity of sepal in whorl 1 . It's co-action with $B$ class genes, PISTILLATA (PI), determines petal identity in whorl 2. Further the interaction of class B TFs with class C, AGAMOUS $(A G)$, determines stamen identity in whorl 3. Carpel identity in whorl 4 specified by $A G$ itself. AP2 which belong to Class A gene, interacts with class $C$ gene and $A G$ by suppressing each other's roles in order to determine the identities and properties of the reproductive organs and perianth (Zhao et al., 2007; Krizek and Anderson, 2013). Loss-of-function of AP2 turns sepals and petals into carpels since there are in excess of AG activity into the outer two whorls of the flower (Wollmann et al., 2010; Zhu and Helliwell, 2011; Huang et al., 2016).

Most of the miRNA targets are TFs which regulate plant growth and developments (Li and Zhang, 2016; Shriram et al., 2016; Shu et al., 2016). One of the important plant developmental processes is flowering stage, which is regulated by complex gene 
networks that integrate multiple environmental and endogenous cues to ensure flowering at the appropriate time (Yamaguchi et al., 2009; Spanudakis and Jackson, 2014). This mechanism is eventually regulated by the induction and activity of three main TFs; LEAFY (LFY), FRUITFULL (FUL), and APETALA1 (AP1) (Terzi and Simpson, 2008; Zhou and Wang, 2013). Among these three genes, LFY has been considered to play a role as major regulator, since, the loss of LFY function causes the most remarkable delay in flowering process (Lee and Lee, 2010; Tang et al., 2016; Yamaguchi et al., 2016). However, these three genes are controlled by TF SQUAMOSA PROMOTER BINDING PROTEINLIKE 3 (SPL3). In general, SQUAMOSA PROMOTER BINDING PROTEINLIKE (SPL) genes are featured by their SQUAMOSA PROMOTER-BINDING (SBP) domain, which consists of a novel zinc finger with two zinc ion binding sites (Yamasaki et al., 2004; Wang et al., 2015).

TCP TF contains a TCP domain, which codes a motif that is predicted to form basic helix-loop-helix structure known for distinct DNA-binding domains (Kosugi and Ohashi, 2002; $\mathrm{Li}, 2015)$. TCP TF is named after the first four characterized members, namely TEOSINTE BRANCHED1 (TB1) from maize, CYCLOIDEA (CYC) from snapdragon, and PROLIFERATING CELL NUCLEAR ANTIGEN FACTOR1 (PCF1) from rice (Danisman et al., 2013; Li, 2015). Previous finding unravel that TCP have been involved in different ways to promote leaf development by cell division, growth, and differentiation (Sarvepalli and Nath, 2011). TCP TFs also involve in flower development (Nag et al., 2009; Sarvepalli and Nath, 2011; De Paolo et al., 2015), leaf senescence (Schommer et al., 2008; Li, 2015), auxin and jasmonic acid signaling (Schommer et al., 2008; Koyama et al., 2010; Ma et al., 2014), development of male and female gametophyte (Takeda et al., 2006; Li, 2015), mitochondrial biogenesis (Abe et al., 2010; Welchen et al., 2013), and interaction with the circadian clock (Giraud et al., 2010; Li, 2015). In Arabidopsis, there are 24 predicted TCP proteins. These predicted TCP were classified into two groups; class I and class II proteins. Class I made up of 13 proteins, whereas, remaining 11 proteins were placed in class II proteins. Both of these classes act as activator and repressor (Aguilar Martinez and Sinha, 2013; Manassero et al., 2013).

WRKY TFs belong to huge and diverse family of TFs. Till now, 74 members had been identified in A. thaliana and 109 in O. sativa (Eulgem and Somssich, 2007; Phukan et al., 2016). Members of this family have at least one conserved DNA-binding region, WRKY domain, comprising of a conserved WRKYGQK peptide sequence and a zinc finger motif. In general, this domain binds to the W box, a DNA element, even though alternative binding sites also have been identified (Ciolkowski et al., 2008; Rinerson et al., 2015). WRKY TFs involve in various networks in genetic system to govern multiple responses at once; whether it is biotic and abiotic stresses, or physiological (Banerjee and Roychoudhury, 2015; Phukan et al., 2016). Besides, WRKY TFs are also responsible to regulate production of some secondary metabolites such as phenolic compounds along with lignin, flavanols, and tannins (Guillaumie et al., 2010; Wang et al., 2010; Phukan et al., 2016).
NAC [no apical meristem (NAM), Arabidopsis transcription activation factor [ATAF1/2], and cup-shaped cotyledon (CUC2)] are among of major families of transcriptional regulators in plants, and present in a wide range of land plants (Olsen et al., 2005; Jensen et al., 2010; Hu et al., 2015). In Arabidopsis, 9 of the 10 , NAC domains are known to bind with conserved DNA target sequence having a CGT[GA] core with different affinity levels (Jensen et al., 2010; Lindemose et al., 2014). Interestingly, NAC TFs play diverse roles in plant system which includes; regulation of plant development and responses to biotic and abiotic stresses (Feng et al., 2014; Hu et al., 2015).

Plant-specific TFs, growth-regulating factor (GRF) were initially identified for their role in developing stem and leaf. But later studies revealed that in addition to stem and leaves, other important for other developmental processes including root growth, flower and seed development, and plant responses under extreme environmental conditions (Kim et al., 2003; Kim and Kende, 2004; Omidbakhshfard et al., 2015). GRF forms complexes by combining with GRF-interacting factors (GIFs), a type of transcriptional co-activators (Kim and Kende, 2004; Debernardi et al., 2014).

Homeo domain-leucine zipper (HD-Zip) proteins are among the TFs that belong to plants kingdom. In A. thaliana, these TFs are encoded by more than 25 genes. Two important domains HDZip proteins are characterized by the presence of a homeo domain (HD) and a leucine zipper domain (Zip) which are responsible for DNA binding and involved in protein-protein interaction, respectively (Wang et al., 2013; Mao et al., 2016). Based on previous sequence similarities findings, these proteins have been divided into four groups. Among these groups, HD-Zip I proteins are involved in plant responses related to abiotic stress, blue light, de-etiolation, abscisic acid ( $\mathrm{ABA})$, and embryogenesis. Second group, HD-Zip II proteins take part in auxin signaling, light response, and shade avoidance. Similarly, HD-Zip III governs embryogenesis, lateral organ initiation, leaf polarity, and meristem function. Whereas, HD-Zip IV proteins play important role during trichome formation, root development, differentiation of epidermal cells, and anthocyanin accumulation (Turchi et al., 2015; Mao et al., 2016).

\section{miRNAs AND TFs: PARTNERSHIP IN PLANT GENE REGULATION}

It is essential to illustrate an integrated picture for the regulatory relationships between miRNAs, TFs, and target genes. However, it is quite difficult to develop a clear cut regulatory relationship between miRNAs and TFs, because, in addition to the interaction of these regulators with their target genes, they sometimes interact with each other; leading to some different results. Here, we have summarized the similarities (Table 1) and differences (Table 2) between miRNAs and TFs mediated regulatory system. We also propose a model to relate these two regulators with their target genes and the consequences of this model to the plant regulatory network under normal (Figure 1) and stress condition (Figure 2). The existence of both miRNAs and TFs in gene regulatory networks will reveal the regulatory role 
TABLE 1 | Similarities between microRNA (miRNA) and transcription factor (TF) in plant.

\begin{tabular}{|c|c|c|}
\hline Factors & miRNA and TF & Reference \\
\hline Gene regulator & Both are gene regulators & Lai et al., 2016 \\
\hline Stimulus response & Both are inducible toward external stimuli & Nazarov et al., 2013 \\
\hline Number of targets & Both can regulate from single to multiple targets at a time & Lindemose et al., 2014 \\
\hline
\end{tabular}

TABLE 2 | Differences between miRNA and TF in plant.

\begin{tabular}{|c|c|c|c|}
\hline Factors & miRNA & TF & Reference \\
\hline Biogenesis & $\begin{array}{l}\text { Synthesized from a series of cleavage } \\
\text { mediated by } D C L\end{array}$ & $\begin{array}{l}\text { Synthesized directly from gene and } \\
\text { undergo folding process }\end{array}$ & $\begin{array}{l}\text { Rogers and Chen, 2013; } \\
\text { Boeva, } 2016\end{array}$ \\
\hline Molecular composition & Short non-coding RNA & Proteins & $\begin{array}{l}\text { Rogers and Chen, 2013; } \\
\text { Boeva, } 2016\end{array}$ \\
\hline Level of regulation & Post-transcription & Transcription & $\begin{array}{l}\text { Rogers and Chen, 2013; } \\
\text { Boeva, } 2016\end{array}$ \\
\hline Functional requirement & $\begin{array}{l}\text { Need Argonoute protein to be fully } \\
\text { functioned }\end{array}$ & $\begin{array}{l}\text { No need additional protein to be fully } \\
\text { functioned }\end{array}$ & $\begin{array}{l}\text { Boeva, 2016; Miyoshi et al., } \\
2016\end{array}$ \\
\hline Mode of action & $\begin{array}{l}\text { Repress the target gene by } \\
\text { cleavage/translational inhibition }\end{array}$ & $\begin{array}{l}\text { Bind to promoter region to activate or } \\
\text { repress the target gene }\end{array}$ & $\begin{array}{l}\text { Brodersen et al., 2008; Rogers } \\
\text { and Chen, 2013; Boeva, } 2016\end{array}$ \\
\hline Target region & Bind to the UTR or coding region & Cis region of promoter & $\begin{array}{l}\text { Rogers and Chen, 2013; } \\
\text { Boeva, } 2016\end{array}$ \\
\hline Family classification & Based on sequence conservation & Based on DNA-binding domain & $\begin{array}{l}\text { Kozomara and Griffiths-Jones, } \\
\text { 2014; Salih et al., } 2016\end{array}$ \\
\hline
\end{tabular}

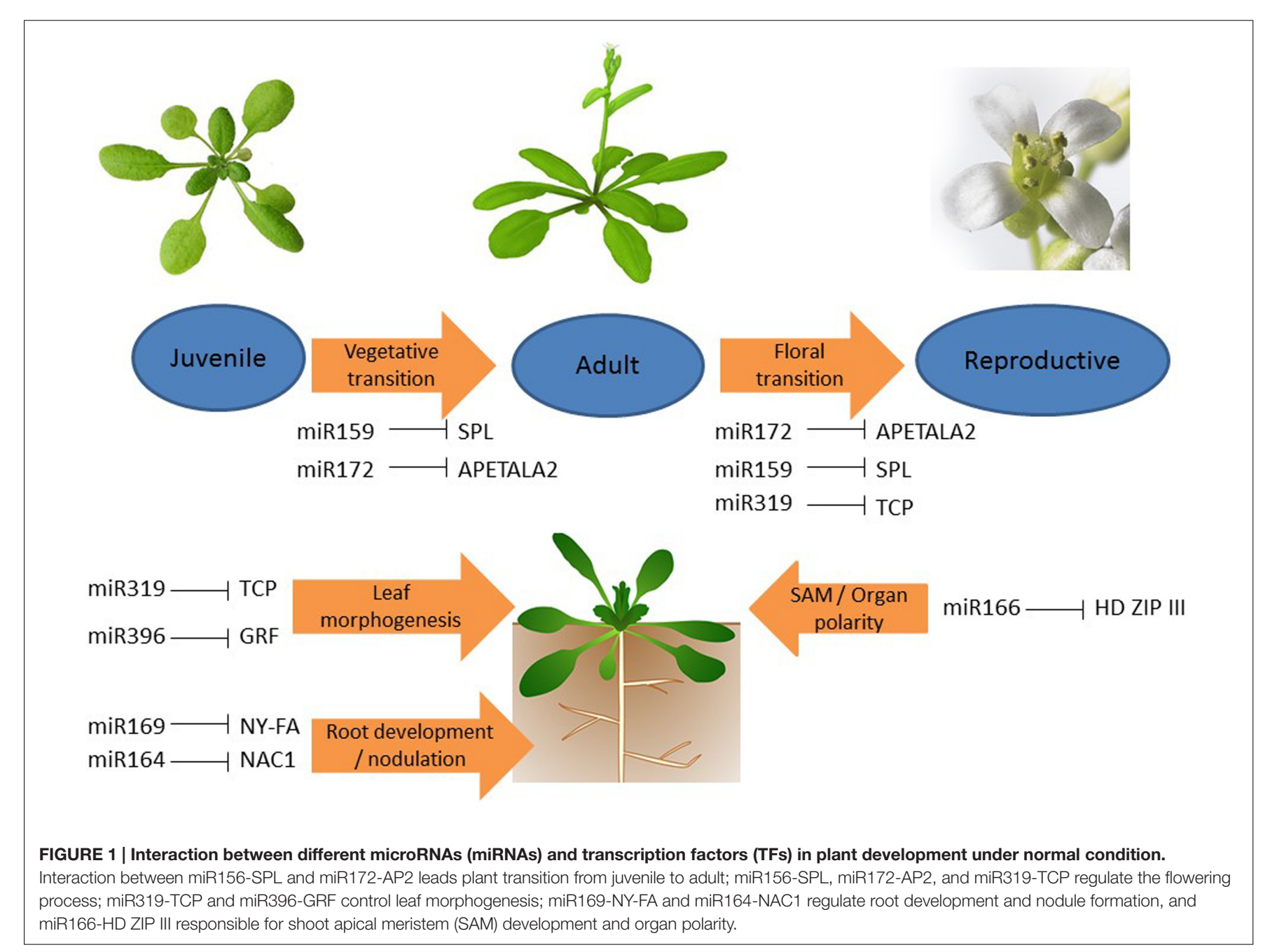




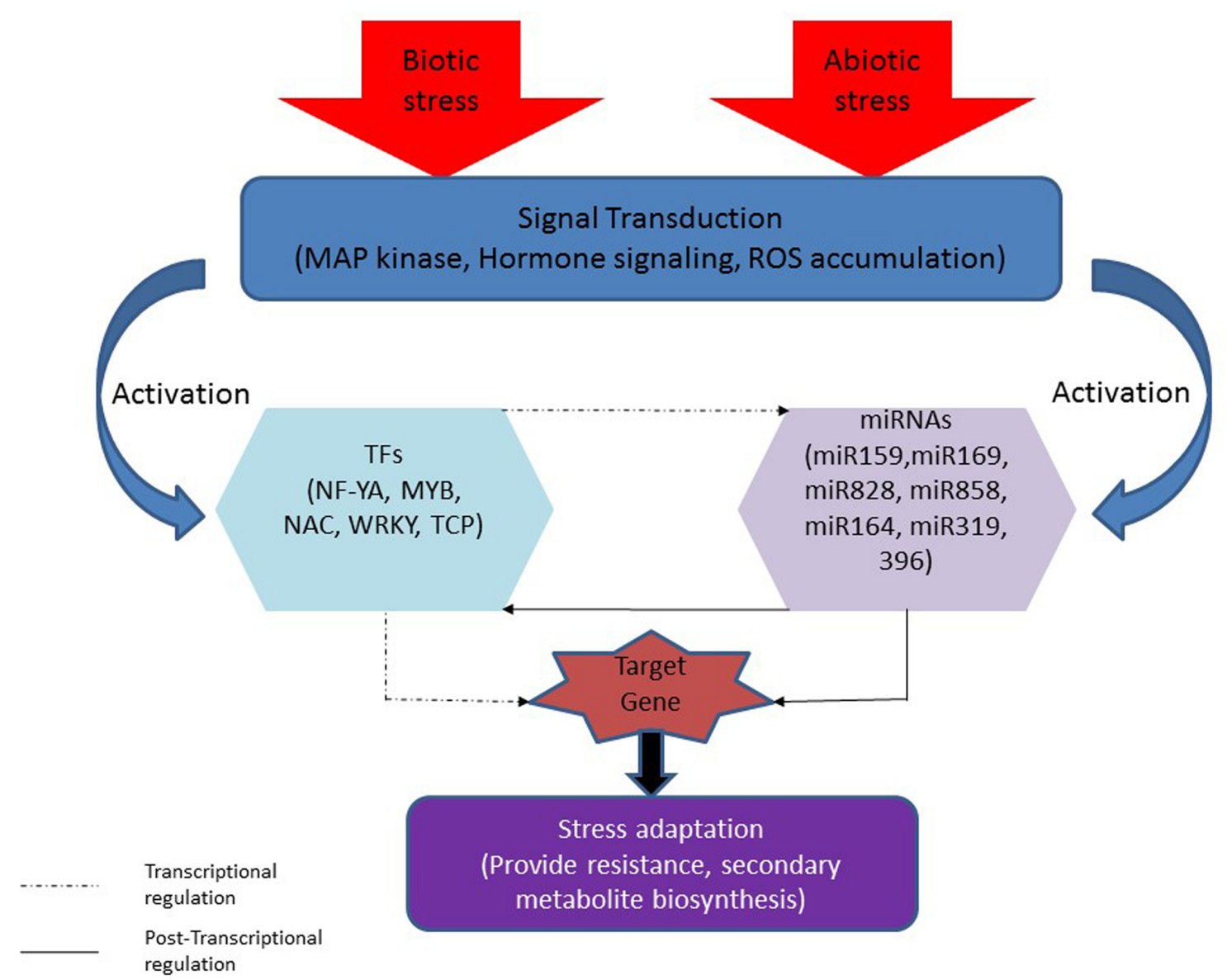

FIGURE 2 | Interaction between different miRNAs and TFs in plant under stresses. Stresses (biotic and abiotic) induce signal transduction which led to activation of stress responsive miRNAs (miR159, miR169, miR828, miR858, miR164, miR319, and miR396) and/or their target TFs (NF-YA, MYB, NAC, WRKY, and TCP) that can affect the target genes. miRNA can regulate target gene directly (post-transcriptionally as shown with dotted line) or through TF by regulating TF (Transcriptionally as shown with solid line) that involve in the regulation of target gene. TFs can directly regulate target gene or through miRNA that involve in the regulation of target gene.

involving both direct and indirect regulatory relationships. In this review, we have tried to bring together previous findings, related to the interaction between miRNAs and TFs, mostly in model plants and some non-model plant (Table 3). Rigorous and time consuming web lab/experimental work was a big hurdle in developing interactions between miRNAs and TFs in plants (Le et al., 2013). But now, with the advancement in the public data bases and bioinformatics tools, to develop an interaction between above mentioned regulators it is relatively easy.

\section{miRNAs AND TFs DURING PLANT GROWTH AND DEVELOPMENT}

Plant growth and development are reflection of genes expression. Appropriate timing and pattern of gene expression and production of proteins are required to ensure proper growth and development in plant (Maizel and Weigel, 2004; Dutt et al., 2014). miRNAs and TFs are among the key regulators which determine how gene expression being regulated, thus affect the physiology and phenotype of the plant.

\section{miRNA AND NY-FA: REGULATE ROOT ARCHITECTURE AND FACILITATE NODULE FORMATION}

In Arabidopsis, four isoforms of miR169 were identified to target NF-YA transcription factor. Those miR169 isoforms (miR169defg) and the NF-YA2 TF were recognized to control the root architecture since loss-of-function miR169defg led to improper root initiation (Sorin et al., 2014). On the other hand, interaction of miR169 and NF-YA transcription factor also seems to be affect nodule formation in Arabidopsis. The overexpression of miR169 against NFYA transcription factor family member, HAP2-1, resulted in late nodulation and detained meristem development, thus led to improper development of nodules (Couzigou and Combier, 2016). 
TABLE 3 | The interaction between miRNAs and TFs under normal and stress condition.

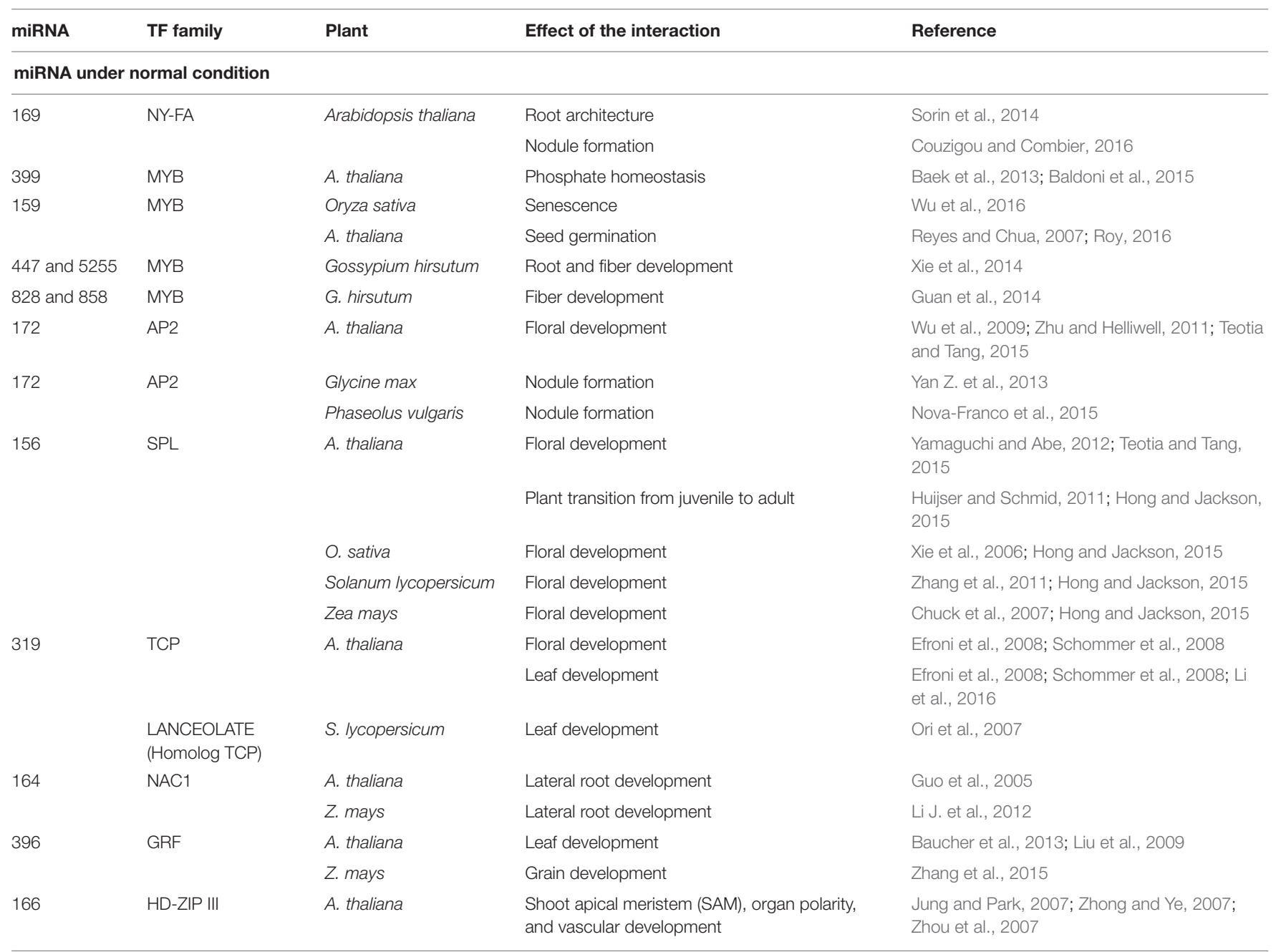

miRNA under stress conditions

\begin{tabular}{|c|c|c|c|c|}
\hline \multirow[t]{3}{*}{169} & NY-FA & A. thaliana & Drought resistance & Li et al., 2008; Ding et al., 2013 \\
\hline & & & Salinity stress & Kong et al., 2014 \\
\hline & & & Abscisic acid response & $\begin{array}{l}\text { Contreras-Cubas et al., 2012; Cheng et al., } \\
2016\end{array}$ \\
\hline \multirow[t]{2}{*}{159} & MYB & A. thaliana & ABA hypersensitivity & Reyes and Chua, 2007; Roy, 2016 \\
\hline & & & ABA hyposensitivity & Alonso-Peral et al., 2010 \\
\hline 858 & MYB & A. thaliana & Flavonoid biosynthesis & Sharma et al., 2016 \\
\hline 828 and 858 & MYB & G. hirsutum & Response to high temperature & Wang Q. et al., 2016 \\
\hline 164 & NAC1 & Triticum aestivum & $\begin{array}{l}\text { Contribute resistance against Puccinia } \\
\text { striiformis f. sp. tritici (Pst) }\end{array}$ & Feng et al., 2014 \\
\hline \multirow[t]{2}{*}{396} & WRKY & O. sativa & Response to arsenic treatment & Liu and Zhang, 2012 \\
\hline & & Helianthus annuus L. & Response to high temperature & Giacomelli et al., 2012 \\
\hline \multirow[t]{2}{*}{319} & TCP & A. thaliana & Jasmonic acid biosynthesis & Schommer et al., 2008 \\
\hline & & S. lycopersicum & Jasmonic acid biosynthesis & Zhao et al., 2015 \\
\hline 164 & NAC & A. thaliana & Drought resistance & Fang et al., 2014 \\
\hline
\end{tabular}




\section{miRNA AND MYB: REGULATE FLOWERING TIME, PHOSPHATE HOMEOSTASIS, LEAF SENESCENCE and ROOT AND FIBER DEVELOPMENT}

Loss-of-function of miR858 plants led to the robust growth and early flowering. Further expression of artificial miRNA (amiRNA) target mimic (MIM858) cause the reduction of plant growth and delayed flowering (Sharma et al., 2016). MYB transcription factor was able to activate miR399, which responsed to phosphate (Pi) starvation in Arabidopsis (Baek et al., 2013). Overexpressing AtMYB2 showed high miR399f expression and tissue Pi contents which may resulted via elevated expression of a subset of Pi starvation-induced genes (Baek et al., 2013; Baldoni et al., 2015).

In maize inbred line, ELS-1, zma-miR159d which targeted MYB transcription factor was significantly downregulated in the leaves during senescence, while in another inbred line, Yu871, zma-miR159d was upregulated (Wu et al., 2016). In cotton, ghr-miR447a and ghr-miR5255a/b/c/e/f/g/h targeted CPC, a type of MYB transcription factor showing that ghr-miR447a and ghr-miR5255a/b/c/e/f/g/h might play a significant role in root and fiber development under drought and salinity stresses by regulating CPC in cotton (Xie et al., 2014). Similar study was carried out in cotton where two miRNAs; miR828 and miR858, targeted MYB2, which is responsible for fiber development (Guan et al., 2014).

\section{miRNAs DETERMINE THE AGE OF THE PLANT}

Couple of decades ago, there had been numerous studies which illustrated that different miRNA families play role in regulating floral timing and development, by targeting transcription factors involved in these processes (Jones-Rhoades et al., 2006; Chuck et al., 2009; Luo et al., 2013; Spanudakis and Jackson, 2014; Hong and Jackson, 2015). At least 11 different miRNA families have been involved in regulating the induction of floral development at each stage. In plant miR156, miR172, and miR390 were involved during transition from juvenile to adult stage. Similarly, in transition from vegetative to reproductive stage, miR159, miR169, miR172, and miR399 were involved. A large group of miRNAs, including; miR159, miR160, miR164, miR166/5, miR167, miR169, miR172, and miR319 regulate flower development stage.

\section{miRNA and AP2: REGULATE FLORAL AND NODULE FORMATION}

In Arabidopsis, miRNA172 targeted mRNA of a floral homeotic gene AP2 that involve in floral development (Wu et al., 2009; Zhu and Helliwell, 2011; Teotia and Tang, 2015). Unlike most plant miRNAs which mostly turn off their own targets by cleavage (Chen, 2004; Ameres and Zamore, 2013; Brousse et al.,
2014; Park and Shin, 2014), miR172 regulate its target via translational inhibition (Chen, 2004; Mlotshwa et al., 2006; Teotia and Tang, 2015). Prominent miRNA172 accumulation causes defect in floral organ identity, which looks similar to those loss-of-function ap2 mutants. High levels of mutant ap2 mRNA with disrupted base for miR172 base pairing resulted floral pattern defects (Chen, 2004; Teotia and Tang, 2015).

In common beans and soybean miR172 and its target; AP2, involved in nodule formation (Yan Z. et al., 2013; Nova-Franco et al., 2015). Nodulation occurs when plant roots establish a symbiotic relationship with nitrogen-fixing bacteria (rhizobia) to obtain nitrogen (Sasaki et al., 2014; Suzaki et al., 2015). Rhizobial infection on bean caused the expression level of miR $172 \mathrm{c}$ to increase until during nodule development stage, while uninfected nodules show low level of miR172c and high level of AP2. In addition, overexpression of miR172c resulted in enhanced root growth, improved rhizobial infection, improved expression of early nodulation and autoregulation of nodulation genes, and improved nodulation and nitrogen uptake (Nova-Franco et al., 2015).

\section{miRNA AND SPL: REGULATE PLANT TRANSITION FROM JUVENILE TO ADULT}

In Arabidopsis, SPL gene family is a well evident target of miR156. Out of 17 SPL genes, 11 have been reported as downregulated by miR156 through mRNA cleavage and translational inhibition (Yamaguchi and Abe, 2012; Teotia and Tang, 2015; Wang et al., 2015). A reduced level of miR156 over time with increasing plant age, resulted in increased expression level of SPL transcription factors which induced flowering through the activation of FT, LFY, and MADS-box gene (Yamaguchi and Abe, 2012; Teotia and Tang, 2015). In contrast, overexpressing miR156 in transgenic plant resulted delayed flowering and extended juvenile phase (Huijser and Schmid, 2011; Hong and Jackson, 2015). Interestingly, miR156 was downregulated when temperature was increased by elevated carbon dioxide concentration (May et al., 2013). miR156 have conserved role in regulating flowering in rice, tomato, and maize (Xie et al., 2006; Chuck et al., 2007; Zhang et al., 2011; Hong and Jackson, 2015).

\section{miRNA AND TCP: REGULATE LEAF MORPHOGENESIS}

In Arabidopsis, role of TCPs and their regulation by miR319 was first identified using microarray in jaw-D mutants (JonesRhoades et al., 2006; Schommer et al., 2012; Spanudakis and Jackson, 2014). Overexpressing miR319 in Arabidopsis mutants delayed the flowering phenotype in long day conditions (Terzi and Simpson, 2008; Spanudakis and Jackson, 2014). Lateflowering phenotype was observed due to loss-of-function; 
where miR319 had targeted TCP4 (Sarvepalli and Nath, 2011; Spanudakis and Jackson, 2014). Another functional analysis revealed that loss-of-function of miR319, which was regulating TCP genes, led to slightly increase in the leaves size (Schommer et al., 2008). Additionally, misexpression of tissue-specific promoters at later stages of leaf development had significantly reduced the leaf size in Arabidopsis (Efroni et al., 2008; Li et al., 2016). Beside, miRNA319 targeted TCPs which involved in regulation of KNOTTED1-Like HOMEOBOX (KNOX) genes, BREVIPEDICELLUS $(B P)$ and KNAT2 through ASYMMETRIC LEAVES 2 (AS2) which can affect the leaf morphogenesis (Li Z. et al., 2012). Recent study reported that TCP transcription factor was regulated by RABBIT EARS (RBE) during leaf development (Li et al., 2016). In tomato, overexpression of miR319 resulted into formation of a giant tomato leaf (Ori et al., 2007; Parapunova et al., 2014).

\section{INTERACTION BETWEEN MiR159-MYB AND miR319-TCP}

In model plant, Arabidopsis, miR159 and miR319 targeted the MYB and TCP transcription factors, respectively. Interestingly, both miRNA-target nodes had abilities to regulate miR167 and the target, ARF6/ARF8 node (Rubio-Somoza and Weigel, 2013). The direct interaction of MYB and TCP transcription factor may contribute to the functional redundancy (RubioSomoza and Weigel, 2013; Spanudakis and Jackson, 2014). Regardless of high sequence similarity of these miRNAs, the regulation of target TCP and MYB transcripts remain conserved for each miRNA families. Although, miR319 was able to bind MYB transcripts, but it exhibited an incomplete temporal and spatial expression pattern corresponding to miR159. On the other hand, miR159 was unable to bind TCP transcripts. This unique interaction suggested that miR159 and miR319 were able to perform different regulatory roles in plant development (Palatnik et al., 2007; Spanudakis and Jackson, 2014).

\section{miRNA and NAC: REGULATE LATERAL ROOT FORMATION}

Previous evidences suggested that NAC TFs could enhance lateral root development (Xie et al., 2000; He et al., 2005; Li J. et al., 2012; Couzigou and Combier, 2016). In Arabidopsis, endogenous and transgenic NAC1 transcript were cleavaged by miR164, producing a 39 nucleotide long specific fragments. However, the action of miR164 was blocked by NAC1 mutations that interrupted the base pairing with miR164. Arabidopsis mir164a and mir164b mutant plants had reduced miR164 expression, thus upregulated NAC1 transcript level, resulting to more lateral roots as compared to wild type plants (Guo et al., 2005). Overexpression of $Z m N A C 1$ in transgenic Arabidopsis had enhanced lateral roots formation in comparison to the wild type plant (Li J. et al., 2012).

\section{miRNA and GRF: REGULATE LEAF MORPHOGENESIS, STEM CELL DEVELOPMENT, AND GRAIN FILLING}

In Arabidopsis, miR396a and miR396b were involved in regulating the leaf morphology by targeting GRF TFs family (Liu et al., 2009; Baucher et al., 2013). Liu and his colleagues, using northern blot hybridizations approach, found that miR396 was predominantly expressed in leaf and seedling. Overexpression of miR396a or miR396b in Arabidopsis resulted into a phenotype with narrow leaves, which probably was due to decreased in cell numbers. The overexpression of miR396 had also led to suppression of six GRF genes and GIF1 which acted as key players in cell division in leaves. Additionally, the overexpression of miR396 resulted in reduced stomata density, a feature that favors drought tolerance in plants. Moreover, additional target for miR396 had been identified which were basic Helix-LoopHelix (bHLH74) TF, required for Arabidopsis normal growth and development (Debernardi et al., 2012). Further, in Populus trichocarpa, precursor of the miR396c, which possess mature sequence identical to miR396b in Arabidopsis, was expressed in tobacco plant using CaMV35S promoter. The transgenic plant exhibited altered organ development, where the third and fourth whorls were turned into stigmatoid anthers and fasciated carpels and delayed the flower development process (Baucher et al., 2013).

Recent findings has discovered that miR396 and GRF regulatory network may regulates the transition of stem cells which are located at specific cellular context or stem cell niche (SCN) to transit-amplifying cells (TACs) in the Arabidopsis root meristem (Rodriguez et al., 2015). In SCN, miR396 is expressed, but in TACs GRFs are expressed. The GRFs are essential for the function of the TACs. Low expression level of GRFs in TACs resulted in a low rate of the cell cycle. Additionally, it would affect TACs by generating periclinal cell divisions typical of stem cells. In opposite, the regulation of miR396 is required to repress the GRFs from the SCN (Rodriguez et al., 2015).

In maize, in an attempt was carried out to explore the profile changes profiles of miR396 and GRF TF and also to analyze their potential regulatory roles during maize effective grain filling period (Zhang et al., 2015). RNA sequencing was carried out in developing maize. It was observed that miR396 was highly expressed at initial stages, and gradually declined during later grain filling stages. By contrast, its target GRF TF was initially negatively regulated, decreased at the beginning, but increased continuously at later stages. Further analysis of expression pattern provide the information that other miRNAs like miR319, miR166, and RNA dependent RNA polymerase may involve in the interaction between miR396 and GRF TF during grain development in maize (Zhang et al., 2015). Similar study was carried out in rice, where LOC_Os02g47280, which is responsible for grain shape, was downregulated by miR396 (Zhang et al., 2013). The evidences obtained from A. thaliana, Zea mays, and O. sativa clearly support that networking between miR396 and GRF TF plays an important role in plant leaf growth and grain development. 


\section{miRNA and HD-ZIP: REGULATE SHOOT APICAL MERISTEM and VASCULAR PATTERNING DEVELOPMENT}

Among four classes of HD-Zip TFs, the interaction of HD-Zip III with miRNA families, 165 and 166 , has been well studied (Bao et al., 2004; Bowman, 2004; Du et al., 2011; Ramachandran et al., 2016). In Arabidopsis, an overexpression of miR166 had downregulated three HD-ZIP III genes; ATHB-9/PHV, ATHB$14 / P H B$, and $A T H B-15$, resulting in recapitulate phenotypes. The same phenotype was also observed in loss-of-function mutations of these genes (Zhong and Ye, 2007). Similarly, overexpression of miR165 had turned off all five HD-ZIP III genes, which led to recapitulated phenotypes caused by loss-of-function of mutations of hd-zip III genes, such as loss of shoot apical meristem (SAM), changed in organ polarity and defects in vascular tissues development and inter fascicular fibers (Zhong and Ye, 2007; Zhou et al., 2007). Beside, miR165 and miR166 were also reported to regulate SAM and floral development through WUSCHEL (WUS)-CLAVATA (CLV) pathway (Jung and Park, 2007). Although miR165 and miR166 target the same genes, individual miR165 and miR166 display different expression domains in different part of plant tissues. For instances, overexpression of miR165 and miR166 plant resulted in the alterations in SAM activities and floral formation (Jung and Park, 2007; Zhang and Zhang, 2012).

Additionally, in both Arabidopsis and maize, miR165 and 166 were observed with abundance on the abaxial side of leaf, and in developing phloem of the leaf primordium, since both miRNAs play critical role in leaf asymmetry patterning. Adaxialization and overexpression of the rolled leaf 1 gene occur when miRNA target site of a REV homolog was mutated in maize rolled leaf1 (rld1) mutant (Juarez et al., 2004; Ramachandran et al., 2016). Hence, in both eudicots and monocots, HD-ZIP III which is responsible for vascular patterning of leaves and stems has been suppressed by miRNA from abaxial domains (Ramachandran et al., 2016).

\section{miRNAs UNDER STRESS RESPONSE}

MicroRNAs and TFs are the gene regulators which play an important role under biotic and abiotic stresses in plant. In this section, we have summarized latest information on the interaction between miRNAs and TFs under biotic and abiotic stresses and their effect on phenotypic and physiological changes in plants.

\section{MIRNA AND NY-FA: CONTRIBUTE DROUGHT RESISTANCE}

In Arabidopsis, interaction between miR169 and NF-YA transcription factor regulates the drought tolerance ( $\mathrm{Li}$ et al., 2008; Ding et al., 2013). Coexpression of miR169 members and NFYA5 revealed that miR169a was more effective than miR169c in suppressing the NFYA5 at mRNA level. Arabidopsis nfya5 mutants and transgenic plants overexpressing miR169a showed more susceptibility toward drought as compared to wild type plants. In contrast, overexpression of NFYA5, resulted plants with enhanced drought tolerance. However, during salinity stress, miR169 was significantly induced which halted the expression of nfya5 in Arabidopsis (Kong et al., 2014). In addition, ABA treatment to the Arabidopsis had significantly induced NFYA5 TF and caused the downregulated of miR169 level (Contreras-Cubas et al., 2012; Cheng et al., 2016).

\section{MIRNA AND MYB: INVOLVED IN FLAVONOID BIOSYNTHESIS PATHWAY AND RESPONSE TO HIGH TEMPERATURE}

A study had been carried out to functionally characterized miR858a in Arabidopsis. The miR858a, which putatively targets R2R3-MYB transcription factors involved in flavonoid biosynthesis (Sharma et al., 2016). Overexpression of miR858a in Arabidopsis resulted in the downregulation of several MYB TFs involved in flavonoid biosynthesis pathway, hence decrease the flavonoid production. In contrast, knockdown of miR858a by target mimic led to plant growth reduction and delayed flowering (Sharma et al., 2016).

In cotton, MYB TF was found to be upregulated in response to high temperature. Like the previous study (Guan et al., 2014), MYB TF was targeted by miR828a and miR858 (Wang Q. et al., 2016). From this finding, we suggest MYB TF and miR828 and miR858 may have dual role in cotton, during fiber development and adaptation against high temperature.

\section{MIRNA AND WRKY: RESPONSE TO HIGH TEMPERATURE}

In sunflower, when plant exposed to high temperatures, a WRKY TF (HaWRKY6) exhibited inverse correlation with miR396. High level of miR396 was observed in older leaves in contrast to the distal portion where the expression was low (Giacomelli et al., 2012). In rice treated with arsenic, miR396 was downregulated which resulted in the upregulation of its target, WRKY TF (Liu and Zhang, 2012). Currently, as per our knowledge, no functional study involving the overexpression or loss-of-function of miRNA and WRKY TF has been carried out.

\section{miRNA AND TCP: REGULATE JASMONIC ACID BIOSYNTHESIS}

Last decade, a combination of genome-wide, biochemical and genetic studies discovered TCP were responsible for the jasmonic acid biosynthesis (Schommer et al., 2008). Leaf extracts analysis from plants with high activity of miR319 regulate the expression of the biosynthetic genes, which subsequently led to change in jasmonic acid levels. Moreover, recent finding demonstrated that root-knot nematode $(\mathrm{RKN})$ resistance in tomato was established by using reverse genetic approaches in the interaction of miR319 
and TCP4 (Zhao et al., 2015). These interactions affected both jasmonic acid synthetic genes and the endogenous jasmonic acid level in leaves. These finding suggest that the negative interaction between miR319 and TCP4 acted as a systemic signal responder and regulator that modulated the systemic defensive response, mediated via jasmonic acid responsive to RKN (Zhao et al., 2015).

\section{miRNA AND NAC: REGULATE DROUGHT RESISTANCE AND CONTRIBUTE RESISTANCE AGAINST FUNGUS}

The interaction between miR164 and NAC TF is well known in developmental process in Arabidopsis. In addition to that, miR164 and NAC TFs play an important role in regulating drought resistance in rice; where overexpression of miR164 against NAC TFs led to susceptibility toward drought (Fang et al., 2014).

In wheat, interaction between miR164 and novel TF NAC21/22 was confirmed experimentally via co-transformation of both genes in tobacco leaves. Transcript accumulation of NAC21/22 and miR164 exhibited contrasting expression patterns in wheat response to Puccinia strifformis f. sp. tritici (Pst). Silencing of the NAC21/22 showed reduced stripe rust resistance in wheat. These results indicate that the target of miR164 is a novel NAC TF from wheat and plays an essential role in developing stripe rust resistance in host plants (Feng et al., 2014).

\section{REMARKS, FUTURE PERSPECTIVE, AND POTENTIAL APPLICATION}

\section{miRNA as Secondary Metabolite Regulator}

Gathering all information above, interaction between miRNAs and TFs will help in understanding the regulatory networks influenced directly by these regulators and cross talking between various biological processes in plants. As miRNAs has been found to be related in secondary metabolite regulation which need to be further explored (Bulgakov and Avramenko, 2015). In Arabidopsis, the interaction between miR156 and SPL resulted in the negative regulation of anthocyanin biosynthesis (Gou et al., 2011). Moreover, in Arabidopsis, loss-of-function of miR163 also led to the accumulation of methyl farnesoate. miR163 also found to regulate another mRNA encoding $S$-adenosylmethionine dependent methyltransferases that is responsible for methylation of secondary metabolites and different signaling molecules $(\mathrm{Ng}$ et al., 2011).

In opium, miR13, miR2161, and miR408 were involved in indole alkaloid biosynthesis (Boke et al., 2015). In medicinal herb, Picrorhiza kurroa, miR4995 was involved in the regulation of terpenoid biosynthesis (Vashisht et al., 2015). These interactions can be utilized as a tool to enhance secondary metabolite production either by overexpressing
miRNA or transcription factor. Other approach can be the knockdown of miRNA/TF which interfere in the secondary metabolite production. In Persicaria minor plant, an interaction among different miRNAs and TFs investigated. For instance, the targets of miR156 and miR172 (SPL and AP2) were downregulated, whereas targets of miR858 and miR894 (MYB and WRKY) were upregulated under elicitation by Fusarium oxysporum (Samad et al., 2016). These finding supported the previous studies; especially, in model plant where the TFs that played role in defense mechanism were upregulated while those TFs which mostly involved in plant development were downregulated by miRNA under stress condition.

\section{Artificial miRNA (amiRNA) for Secondary Metabolites and Disease Resistance in Plants}

One of the most important global issues is food security to ensure everyone living in this globe can access sufficient food. Since world population is increasing on an alarming rate every effort must be taken in account to obtain higher food production. Genetic modification technology based on miRNA and TFs approaches, can be one of the solutions that contribute to crop yields directly by developing superior plants which can survive under environmental stresses, with high yield and nutrients. This technology will also promote a healthy environment due to less pesticide usage, and this reduced pesticide cost will be used to elevate the living standard of the poor agricultural community across the globe.

After the breakthrough of miRNA discovery, extensive studies had been done which led to development of new version of miRNA called amiRNA (Carbonell et al., 2014; Shriram et al., 2016). This approach utilize the unique stem-loop structure of endogenous pri-miRNAs, in which the miRNA/miRNA* duplex sequences are being replaced with amiRNA/amiRNA* sequences that direct the silencing of target gene with high efficiency (Eamens et al., 2014). AmiRNA technique exhibited some advantages when compared with conventional RNA interference (RNAi), where amiRNA can be useful for targeting groups of closely related genes, including tandem arrayed and the prediction of gene targeted by amiRNA could be more precise (Schwab et al., 2006; Ossowski et al., 2008; Carbonell et al., 2015). This approach was effectively used for the downregulation of Chalcone synthase genes in Arabidopsis (Niemeier et al., 2010; Kamthan et al., 2015).

Beside, amiRNA can be a new approach for developing pathogen tolerant plants, especially virus (Vu et al., 2013; Ilardi and Tavazza, 2015; Wagaba et al., 2016). T2 transgenic tomato plants expressing amiR-AV1-1 were highly tolerant to Tomato leaf curl New Delhi virus (ToLCNDV), while those plants expressing amiR-AV1-3 showed moderate tolerance (Vu et al., 2013). Moreover, recent study in cassava showed transgenic plants which carry four amiRNA challenged with Cassava brown streak virus (CBSV) and Ugandan cassava brown streak virus (UCBSV) isolates, showed resistance levels that ranged between 20 and 60\% (Wagaba et al., 2016). 


\section{CONCLUSION AND REMARKS}

In the present article, we have reviewed the regulatory relationships between miRNAs and various families of TFs like; NF-YA, MYB, AP2, TCP, WRKY, NAC, GRF, and SPL, from different plant species. The studied interactions between various miRNAs and above mentioned TFs have important roles during drought tolerance, signal transduction and biosynthesis of secondary metabolites, floral development and nodule formation, leaf development, multiple stresses tolerances, lateral root growth, and plant transition from juvenile to adult, respectively. Being the major gene regulators, miRNAs and TFs determine the phenotype, physiology and response to various environmental stresses. Our current review, with lots of newly developed relations between different miRNAs and TFs, will help plant scientists to develop plants with desired phenotypes and stress tolerance ability against particular stress. The plants with stresses tolerance will help to secure the food production for the ever increasing world population. Moreover, some studied interactions have important role in regulation of secondary

\section{REFERENCES}

Abe, M., Yoshikawa, T., Nosaka, M., Sakakibara, H., Sato, Y., Nagato, Y., et al. (2010). WAVY LEAF1, an ortholog of Arabidopsis HEN1, regulates shoot development by maintaining MicroRNA and trans-acting small interfering RNA accumulation in rice. Plant Physiol. 154, 1335-1346. doi: 10.1104/pp.110. 160234

Aguilar Martinez, J., and Sinha, N. (2013). Analysis of the role of Arabidopsis class I TCP genes AtTCP7, AtTCP8, AtTCP22, and AtTCP23 in leaf development. Front. Plant Sci. 4:406. doi: 10.3389/fpls.2013.00406

Ahmed, F., Kaundal, R., and Raghava, G. P. (2013). PHDcleav: a SVM based method for predicting human Dicer cleavage sites using sequence and secondary structure of miRNA precursors. BMC Bioinformatics 14:S9. doi: 10 . 1186/1471-2105-14-s14-s9

Akhtar, M. M., Micolucci, L., Islam, M. S., Olivieri, F., and Procopio, A. D. (2015). Bioinformatic tools for microRNA dissection. Nucleic Acids Res. 44, 24-44. doi: 10.1093/nar/gkv1221

Alonso-Peral, M. M., Li, J., Li, Y., Allen, R. S., Schnippenkoetter, W., Ohms, S., et al. (2010). The microRNA159-regulated GAMYB-like genes inhibit growth and promote programmed cell death in Arabidopsis. Plant Physiol. 154, 757-771. doi: $10.1104 /$ pp.110.160630

Ambawat, S., Sharma, P., Yadav, N. R., and Yadav, R. C. (2013). MYB transcription factor genes as regulators for plant responses: an overview. Physiol. Mol. Biol. Plants 19, 307-321. doi: 10.1007/s12298-013-0179-1

Ameres, S. L., and Zamore, P. D. (2013). Diversifying microRNA sequence and function. Nat. Rev. Mol. Cell Biol. 14, 475-488. doi: 10.1038/ nrm3611

Arribas-Hernández, L., Kielpinski, L. J., and Brodersen, P. (2016). mRNA decay of most Arabidopsis miRNA targets requires slicer activity of AGO1. Plant Physiol. 171, 2620-2632. doi: 10.1104/pp.16.00231

Axtell, M., Westholm, J., and Lai, E. (2011). Vive la difference: biogenesis and evolution of microRNAs in plants and animals. Genome Biol. 12, 221.

Baek, D., Kim, M. C., Chun, H. J., Kang, S., Park, H. C., Shin, G., et al. (2013). Regulation of miR399f transcription by AtMYB2 affects phosphate starvation responses in Arabidopsis. Plant Physiol. 161, 362-373. doi: 10.1104/pp.112. 205922

Bakhshi, B., Mohseni Fard, E., Nikpay, N., Ebrahimi, M. A., Bihamta, M. R., Mardi, M., et al. (2016). MicroRNA signatures of drought signaling in rice root. PLoS ONE 11:e0156814. doi: 10.1371/journal.pone.0156814

Baldoni, E., Genga, A., and Cominelli, E. (2015). Plant MYB Transcription Factors: their role in drought response mechanisms. Int. J. Mol. Sci. 16, 15811. metabolites biosynthesis and can be used as tool for the production of plant based medicinal biomolecules.

\section{AUTHOR CONTRIBUTIONS}

The first version of this manuscript was written by AS, MS, $\mathrm{NN}$, and IF. AM, ZZ, and II revised the manuscript and advised the writing style. All authors made substantial contribution and approved the final version of the manuscript.

\section{ACKNOWLEDGMENTS}

The authors would like to thank Ministry of Higher Education of Malaysia for MyBrain 15 scholarship (MyPhD) awarded to AS and IF. We also would like to extend our appreciation to referees and editors for their suggestions, comments, and critical reviews. This work on miRNA was funded by University Research Grant (DIP-2015-018).

Banerjee, A., and Roychoudhury, A. (2015). WRKY proteins: signaling and regulation of expression during abiotic stress responses. Scientific WorldJournal 2015:807560. doi: 10.1155/2015/807560

Bao, N., Lye, K. W., and Barton, M. K. (2004). MicroRNA binding sites in Arabidopsis class III HD-ZIP mRNAs are required for methylation of the template chromosome. Dev. Cell 7(5), 653-662. doi: 10.1016/j.devcel.2004. 10.003

Baranauske, S., Mickutė, M., Plotnikova, A., Finke, A., Venclovas, Č., Klimašauskas, S., et al. (2015). Functional mapping of the plant small RNA methyltransferase: HEN1 physically interacts with HYL1 and DICER-LIKE 1 proteins. Nucleic Acids Res. 43, 2802-2812. doi: 10.1093/nar/gkv102

Bartel, D. (2004). MicroRNAs: genomics, biogenesis, mechanism, and function. Cell 116, 281-297.

Baucher, M., Moussawi, J., Vandeputte, O. M., Monteyne, D., Mol, A., Perez-Morga, D., et al. (2013). A role for the miR396/GRF network in specification of organ type during flower development, as supported by ectopic expression of Populus trichocarpa miR396c in transgenic tobacco. Plant Biol. (Stuttg) 15, 892-898. doi: 10.1111/j.1438-8677.2012. 00696.x

Beauclair, L., Yu, A., and Bouche, N. (2010). microRNA-directed cleavage and translational repression of the copper chaperone for superoxide dismutase mRNA in Arabidopsis. Plant J. 62, 454-462. doi: 10.1111/j.1365-313X.2010. 04162.x

Bemis, S. M., Lee, J. S., Shpak, E. D., and Torii, K. U. (2013). Regulation of floral patterning and organ identity by Arabidopsis ERECTA-family receptor kinase genes. J. Exp. Bot. 64, 5323-5333. doi: 10.1093/jxb/ert270

Biłas, R., Szafran, K., Hnatuszko-Konka, K., and Kononowicz, A. K. (2016). Cisregulatory elements used to control gene expression in plants. Plant Cell Tissue Organ Cult. 127, 269-287. doi: 10.1007/s11240-016-1057-7

Boeva, V. (2016). Analysis of genomic sequence motifs for deciphering transcription factor binding and transcriptional regulation in eukaryotic cells. Front. Genet. 7:24. doi: 10.3389/fgene.2016.00024

Boke, H., Ozhuner, E., Turktas, M., Parmaksiz, I., Ozcan, S., and Unver, T. (2015). Regulation of the alkaloid biosynthesis by miRNA in opium poppy. Plant Biotechnol. J. 13, 409-420. doi: 10.1111/pbi.12346

Boucas, J., Höpker, K., Chen, S., Herter-Sprie, G., Jokic, M., Riabinska, A., et al. (2012). Posttranscriptional regulation of gene expression-adding another layer of complexity to the DNA damage response. Front. Genet. 3:159. doi: 10.3389/ fgene.2012.00159

Bowman, J. L. (2004). Class III HD-Zip gene regulation, the golden fleece of ARGONAUTE activity? Bioessays 26, 938-942. doi: 10.1002/bies.20103 
Brodersen, P., Sakvarelidze, A. L., Bruun, R. M., Dunoyer, P., Yamamoto, Y. Y., Sieburth, L., et al. (2008). Widespread translational inhibition by plant miRNAs and siRNAs. Sci. Signal. 320, 1185-1190.

Brogna, S., and Wen, J. (2009). Nonsense-mediated mRNA decay (n.d.) mechanisms. Nat. Struct. Mol. Biol. 16, 107-113.

Brousse, C., Liu, Q., Beauclair, L., Deremetz, A., Axtell, M. J., and Bouche, N. (2014). A non-canonical plant microRNA target site. Nucleic Acids Res. 42, 5270-5279. doi: 10.1093/nar/gku157

Bulgakov, V. P., and Avramenko, T. V. (2015). New opportunities for the regulation of secondary metabolism in plants: focus on microRNAs. Biotechnol. Lett. 37, 1719-1727. doi: 10.1007/s10529-015-1863-8

Cammaerts, S., Strazisar, M., De Rijk, P., and Del Favero, J. (2015). Genetic variants in microRNA genes: impact on microRNA expression, function, and disease. Front. Genet. 6:186. doi: 10.3389/fgene.2015.00186

Carbonell, A., Fahlgren, N., Mitchell, S., Cox, K. L., Reilly, K. C., Mockler, T. C., et al. (2015). Highly specific gene silencing in a monocot species by artificial microRNAs derived from chimeric miRNA precursors. Plant J. 82, 1061-1075. doi: $10.1111 /$ tpj. 12835

Carbonell, A., Takeda, A., Fahlgren, N., Johnson, S. C., Cuperus, J. T., and Carrington, J. C. (2014). New generation of artificial MicroRNA and synthetic Trans-Acting small interfering RNA vectors for efficient gene silencing in Arabidopsis. Plant Physiol. 165, 15-29. doi: 10.1104/pp.113.234989

Chang, S. S., Zhang, Z., and Liu, Y. (2012). RNA interference pathways in fungi: mechanisms and functions. Annu. Rev. Microbiol. 66, 305-323. doi: 10.1146/ annurev-micro-092611-150138

Chang, Y. F., Imam, J. S., and Wilkinson, M. F. (2007). The nonsense-mediated decay RNA surveillance pathway. Annu. Rev. Biochem. 76, 51-74. doi: 10.1146/ annurev.biochem.76.050106.093909

Chen, X. (2004). A microRNA as a translational repressor of APETALA2 in Arabidopsis flower development. Science 303, 2022-2025. doi: 10.1126/science. 1088060

Cheng, H.-Y., Wang, Y., Tao, X., Fan, Y.-F., Dai, Y., Yang, H., et al. (2016). Genomic profiling of exogenous abscisic acid-responsive microRNAs in tomato (Solanum lycopersicum). BMC Genomics 17:423. doi: 10.1186/s12864-016-2591-8

Chow, C.-N., Zheng, H.-Q., Wu, N.-Y., Chien, C.-H., Huang, H.-D., Lee, T.-Y., et al. (2016). PlantPAN 2.0: an update of plant promoter analysis navigator for reconstructing transcriptional regulatory networks in plants. Nucleic Acids Res. 44, D1154-D1160. doi: 10.1093/nar/gkv1035

Chuck, G., Candela, H., and Hake, S. (2009). Big impacts by small RNAs in plant development. Curr. Opin. Plant Biol. 12, 81-86. doi: 10.1016/j.pbi.2008.09.008

Chuck, G., Meeley, R., Irish, E., Sakai, H., and Hake, S. (2007). The maize tasselseed 4 microRNA controls sex determination and meristem cell fate by targeting Tasselseed6/indeterminate spikelet1. Nat. Genet. 39, 1517-1521. doi: 10.1038/ng.2007.20

Ciolkowski, I., Wanke, D., Birkenbihl, R. P., and Somssich, I. E. (2008). Studies on DNA-binding selectivity of WRKY transcription factors lend structural clues into WRKY-domain function. Plant Mol. Biol. 68, 81-92. doi: 10.1007/s11103008-9353-1

Contreras-Cubas, C., Palomar, M., Arteaga-Vazquez, M., Reyes, J. L., and Covarrubias, A. A. (2012). Non-coding RNAs in the plant response to abiotic stress. Planta 236(4), 943-958. doi: 10.1007/s00425-012-1693-z

Couzigou, J. -M., and Combier, J. -P. (2016). Plant microRNAs: key regulators of root architecture and biotic interactions. New Phytol. 212, 22-35. doi: 10.1111/ nph.14058

Danisman, S., van Dijk, A. D., Bimbo, A., van der Wal, F., Hennig, L., de Folter, S., et al. (2013). Analysis of functional redundancies within the Arabidopsis TCP transcription factor family. J. Exp. Bot. 64, 5673-5685. doi: 10.1093/jxb/ ert337

Dantas Machado, A. C., Zhou, T., Rao, S., Goel, P., Rastogi, C., Lazarovici, A., et al. (2014). Evolving insights on how cytosine methylation affects protein-DNA binding. Brief. Funct. Genomics. 14, 61-73. doi: 10.1093/bfgp/elu040

De Paolo, S., Gaudio, L., and Aceto, S. (2015). Analysis of the TCP genes expressed in the inflorescence of the orchid Orchis italica. Sci. Rep. 5:16265. doi: 10.1038/ srep 16265.

Debernardi, J. M., Mecchia, M. A., Vercruyssen, L., Smaczniak, C., Kaufmann, K., Inze, D., et al. (2014). Post-transcriptional control of GRF transcription factors by microRNA miR396 and GIF co-activator affects leaf size and longevity. Plant J. 79, 413-426. doi: 10.1111/tpj.12567
Debernardi, J. M., Rodriguez, R. E., Mecchia, M. A., and Palatnik, J. F. (2012). Functional specialization of the plant miR396 regulatory network through distinct microRNA-target interactions. PLoS Genet. 8:e1002419. doi: 10.1371/ journal.pgen.1002419

Ding, Y., Tao, Y., and Zhu, C. (2013). Emerging roles of microRNAs in the mediation of drought stress response in plants. J. Exp. Bot. 64, 3077-3086. doi: $10.1093 /$ jxb/ert164

Du, J., Miura, E., Robischon, M., Martinez, C., and Groover, A. (2011). The populus class III HD ZIP transcription factor POPCORONA affects cell differentiation during secondary growth of woody stems. PLoS ONE 6:e17458. doi: 10.1371/ journal.pone.0017458

Dutt, M., Dhekney, S. A., Soriano, L., Kandel, R., and Grosser, J. W. (2014). Temporal and spatial control of gene expression in horticultural crops. Hortic. Res. 1:14047. doi: 10.1038/hortres.2014.47

Duval, I., Lachance, D., Giguère, I., Bomal, C., Morency, M.-J., Pelletier, G., et al. (2014). Large-scale screening of transcription factor-promoter interactions in spruce reveals a transcriptional network involved in vascular development. J. Exp. Bot. 65, 2319-2333. doi: 10.1093/jxb/eru116

Eamens, A. L., McHale, M., and Waterhouse, P. M. (2014). The use of artificial microRNA technology to control gene expression in Arabidopsis thaliana. Methods Mol. Biol. 1062, 211-224. doi: 10.1007/978-1-62703-580-4-11

Eckardt, N. A. (2016). The plant cell reviews small RNA and chromatin dynamics: from small genetic circuits to complex genomes. Plant Cell 28, 269-271. doi: 10.1105/tpc. 16.00113

Edger, P. P., and Pires, J. C. (2009). Gene and genome duplications: the impact of dosage-sensitivity on the fate of nuclear genes. Chromosome Res. 17, 699-717. doi: 10.1007/s10577-009-9055-9

Efroni, I., Blum, E., Goldshmidt, A., and Eshed, Y. (2008). A protracted and dynamic maturation schedule underlies Arabidopsis leaf development. Plant Cell 20, 2293-2306. doi: 10.1105/tpc.107.057521

Erkmann, J. A., and Kutay, U. (2004). Nuclear export of mRNA: from the site of transcription to the cytoplasm. Exp. Cell Res. 296, 12-20. doi: 10.1016/j.yexcr. 2004.03.015

Eulgem, T., and Somssich, I. E. (2007). Networks of WRKY transcription factors in defense signaling. Curr. Opin. Plant Biol. 10, 366-371. doi: 10.1016/j.pbi.2007. 04.020

Fahlgren, N., and Carrington, J. C. (2010). miRNA target prediction in plants. Methods Mol. Biol. 592, 51-57. doi: 10.1007/978-1-60327-005-2-4

Fang, Y., Xie, K., and Xiong, L. (2014). Conserved miR164-targeted NAC genes negatively regulate drought resistance in rice. J. Exp. Bot. 65, 2119-2135. doi: 10.1093/jxb/eru072

Feng, H., Duan, X., Zhang, Q., Li, X., Wang, B., Huang, L., et al. (2014). The target gene of tae-miR164, a novel NAC transcription factor from the NAM subfamily, negatively regulates resistance of wheat to stripe rust. Mol. Plant Pathol. 15, 284-296. doi: 10.1111/mpp.12089

Giacomelli, J. I., Weigel, D., Chan, R. L., and Manavella, P. A. (2012). Role of recently evolved miRNA regulation of sunflower HaWRKY6 in response to temperature damage. New Phytol. 195, 766-773. doi: 10.1111/j.1469-8137.2012. 04259.x

Giraud, E., Ng, S., Carrie, C., Duncan, O., Low, J., Lee, C. P., et al. (2010). TCP transcription factors link the regulation of genes encoding mitochondrial proteins with the circadian clock in Arabidopsis thaliana. Plant Cell 22, 3921-3934. doi: 10.1105/tpc.110.074518

Gonzalez, A., Zhao, M., Leavitt, J. M., and Lloyd, A. M. (2008). Regulation of the anthocyanin biosynthetic pathway by the TTG1/bHLH/Myb transcriptional complex in Arabidopsis seedlings. Plant J. 53, 814-827. doi: 10.1111/j.1365313X.2007.03373.x

Gou, J. Y., Felippes, F. F., Liu, C. J., Weigel, D., and Wang, J. W. (2011). Negative regulation of anthocyanin biosynthesis in Arabidopsis by a miR156-targeted SPL transcription factor. Plant Cell 23, 1512-1522. doi: 10.1105/tpc.111.084525

Guan, X., Pang, M., Nah, G., Shi, X., Ye, W., Stelly, D. M., et al. (2014). miR828 and miR858 regulate homoeologous MYB2 gene functions in Arabidopsis trichome and cotton fibre development. Nat. Commun. 5, 3050. doi: 10.1038/ ncomms4050.

Guillaumie, S., Mzid, R., Mechin, V., Leon, C., Hichri, I., Destrac-Irvine, A., et al. (2010). The grapevine transcription factor WRKY2 influences the lignin pathway and xylem development in tobacco. Plant Mol. Biol. 72, 215-234. doi: $10.1007 / \mathrm{s} 11103-009-9563-1$ 
Gulyaeva, L. F., and Kushlinskiy, N. E. (2016). Regulatory mechanisms of microRNA expression. J. Transl. Med. 14, 143. doi: 10.1186/s12967-016-0893-x

Guo, H., Xie, Q., Fei, J., and Chua, N. (2005). MicroRNA directs mRNA cleavage of the transcription factor NAC1 to downregulate auxin signals for Arabidopsis lateral root development. Plant Cell 17, 1376-1386.

Ha, M., and Kim, V. N. (2014). Regulation of microRNA biogenesis. Nat. Rev. Mol. Cell Biol. 15, 509-524. doi: 10.1038/nrm3838

Hao, Q. N., Zhou, X. A., Sha, A. H., Wang, C., Zhou, R., and Chen, S. L. (2011). Identification of genes associated with nitrogen-use efficiency by genomewide transcriptional analysis of two soybean genotypes. BMC Genomics 12:525. doi: 10.1186/1471-2164-12-525

He, X. J., Mu, R. L., Cao, W. H., Zhang, Z. G., Zhang, J. S., and Chen, S. Y. (2005). AtNAC2, a transcription factor downstream of ethylene and auxin signaling pathways, is involved in salt stress response and lateral root development. Plant J. 44, 903-916. doi: 10.1111/j.1365-313X.2005. 02575.x

Holoch, D., and Moazed, D. (2015). RNA-mediated epigenetic regulation of gene expression. Nat. Rev. Genet. 16, 71-84. doi: 10.1038/nrg3863

Hong, Y., and Jackson, S. (2015). Floral induction and flower formation-the role and potential applications of miRNAs. Plant Biotechnol. J. 13, 282-292. doi: 10.1111/pbi.12340

Hu, W., Wei, Y., Xia, Z., Yan, Y., Hou, X., Zou, M., et al. (2015). Genome-wide identification and expression analysis of the NAC transcription factor family in cassava. PLOS ONE 10:e0136993. doi: 10.1371/journal.pone.0136993

Huang, Z., Shi, T., Zheng, B., Yumul, R. E., Liu, X., You, C., et al. (2016). APETALA2 antagonizes the transcriptional activity of AGAMOUS in regulating floral stem cells in Arabidopsis thaliana. New Phytol. doi: 10.1111/nph.14151 [Epub ahead of print].

Hug, N., Longman, D., and Cáceres, J. F. (2016). Mechanism and regulation of the nonsense-mediated decay pathway. Nucleic Acids Res. 44, 1483-1495. doi: 10.1093/nar/gkw010

Huijser, P., and Schmid, M. (2011). The control of developmental phase transitions in plants. Development 138, 4117-4129. doi: 10.1242/dev.063511

Ilardi, V., and Tavazza, M. (2015). Biotechnological strategies and tools for Plum pox virus resistance: trans-, intra-, cis-genesis, and beyond. Front. Plant Sci. 6:379. doi: $10.3389 /$ fpls.2015.00379

Istrail, S., De-Leon, S.B.-T., and Davidson, E. H. (2007). The regulatory genome and the computer. Dev. Biol. 310, 187-195. doi: 10.1016/j.ydbio.2007.08.009

Jensen, M. K., Kjaersgaard, T., Nielsen, M. M., Galberg, P., Petersen, K., O'Shea, C., et al. (2010). The Arabidopsis thaliana NAC transcription factor family: structure-function relationships and determinants of ANAC019 stress signalling. Biochem. J. 426, 183-196. doi: 10.1042/bj20091234

Ji, L., Liu, X., Yan, J., Wang, W., Yumul, R. E., Kim, Y. J., et al. (2011). ARGONAUTE10 and ARGONAUTE1 regulate the termination of floral stem cells through two microRNAs in Arabidopsis. PLoS Genet. 7:e1001358. doi: 10.1371/journal.pgen.1001358

Jin, J., Tian, F., Yang, D.-C., Meng, Y.-Q., Kong, L., Luo, J., et al. (2017). PlantTFDB 4.0: toward a central hub for transcription factors and regulatory interactions in plants. Nucleic Acids Res. 45, D1040-D1045. doi: 10.1093/nar/ gkw982

Jones-Rhoades, M., Bartel, D., and Bartel, B. (2006). MicroRNAS and their regulatory roles in plants. Annu. Rev. Plant Biol. 57, 19-53.

Juarez, M. T., Kui, J. S., Thomas, J., Heller, B. A., and Timmermans, M. C. (2004). microRNA-mediated repression of rolled leaf1 specifies maize leaf polarity. Nature 428, 84-88. doi: 10.1038/nature02363

Jung, J. H., and Park, C. M. (2007). MIR166/165 genes exhibit dynamic expression patterns in regulating shoot apical meristem and floral development in Arabidopsis. Planta 225, 1327-1338. doi: 10.1007/s00425-0060439-1

Kamthan, A., Chaudhuri, A., Kamthan, M., and Datta, A. (2015). Small RNAs in plants: recent development and application for crop improvement. Front.Plant Sci. 6:208. doi: 10.3389/fpls.2015.00208

Kim, J. H., Choi, D., and Kende, H. (2003). The AtGRF family of putative transcription factors is involved in leaf and cotyledon growth in Arabidopsis. Plant J. 36, 94-104.

Kim, J. H., and Kende, H. (2004). A transcriptional coactivator, AtGIF1, is involved in regulating leaf growth and morphology in Arabidopsis. Proc. Natl. Acad. Sci. U.S.A. 101, 13374-13379. doi: 10.1073/pnas.0405450101
Kong, X., Zhang, M., Xu, X., Li, X., Li, C., and Ding, Z. (2014). System analysis of microRNAs in the development and aluminium stress responses of the maize root system. Plant Biotechnol. J. 12, 1108-1121. doi: 10.1111/pbi.12218

Kosugi, S., and Ohashi, Y. (2002). DNA binding and dimerization specificity and potential targets for the TCP protein family. Plant J. 30, 337-348. doi: 10.1046/ j.1365-313X.2002.01294.x

Koyama, T., Mitsuda, N., Seki, M., Shinozaki, K., and Ohme-Takagi, M. (2010). TCP transcription factors regulate the activities of ASYMMETRIC LEAVES1 and miR164, as well as the auxin response, during differentiation of leaves in Arabidopsis. Plant Cell 22, 3574-3588. doi: 10.1105/tpc.110.075598

Kozomara, A., and Griffiths-Jones, S. (2014). miRBase: annotating high confidence microRNAs using deep sequencing data. Nucleic Acids Res. 42, D68-73. doi: 10.1093/nar/gkt1181

Krizek, B. A., and Anderson, J. T. (2013). Control of flower size. J. Exp. Bot. 64, 1427-1437. doi: $10.1093 / \mathrm{jxb} / \mathrm{ert} 025$

Krol, J., Loedige, I., and Filipowicz, W. (2010). The widespread regulation of microRNA biogenesis, function and decay. Nat. Rev. Genet. 11, 597-610. doi: $10.1038 / \mathrm{nrg} 2843$

Lai, X., Wolkenhauer, O., and Vera, J. (2016). Understanding microRNA-mediated gene regulatory networks through mathematical modelling. Nucleic Acids Res. 44, 6019-6035. doi: 10.1093/nar/gkw550

Le, T. D., Liu, L., Liu, B., Tsykin, A., Goodall, G. J., Satou, K., et al. (2013). Inferring microRNA and transcription factor regulatory networks in heterogeneous data. BMC Bioinformatics 14:92. doi: 10.1186/1471-2105-14-92

Lee, J., and Lee, I. (2010). Regulation and function of SOC1, a flowering pathway integrator. J. Exp. Bot. 61, 2247-2254. doi: 10.1093/jxb/erq098

Lelli, K. M., Slattery, M., and Mann, R. S. (2012). Disentangling the many layers of eukaryotic transcriptional regulation. Annu. Rev. Genet. 46, 43-68. doi: 10. 1146/annurev-genet-110711-155437

Levine, M., and Davidson, E. H. (2005). Gene regulatory networks for development. Proc. Natl. Acad. Sci. U.S.A. 102, 4936-4942. doi: 10.1073/pnas. 0408031102

Li, C., and Zhang, B. (2016). MicroRNAs in control of plant development. J. Cell. Physiol. 231, 303-313. doi: 10.1002/jcp.25125

Li, J., Guo, G., Guo, W., Guo, G., Tong, D., Ni, Z., et al. (2012). miRNA164-directed cleavage of ZmNAC1 confers lateral root development in maize (Zea mays L.). BMC Plant Biol. 12:220. doi: 10.1186/1471-2229-12-220

Li, J., Han, S., Ding, X., He, T., Dai, J., Yang, S., et al. (2015). Comparative transcriptome analysis between the cytoplasmic male sterile line NJCMS1A and its maintainer NJCMS1B in soybean (Glycine max (L.) Merr.). PLoS ONE 10:e0126771. doi: 10.1371/journal.pone.0126771

Li, J., Wang, Y., Zhang, Y., Wang, W., Irish, V. F., and Huang, T. (2016). RABBIT EARS regulates the transcription of TCP4 during petal development in Arabidopsis. J. Exp. Bot. 67, 6473-6480. doi: 10.1093/jxb/erw419

Li, S. (2015). The Arabidopsis thaliana TCP transcription factors: a broadening horizon beyond development. Plant Signal. Behav. 10:e1044192. doi: 10.1080/ 15592324.2015 .1044192

Li, S., Liu, L., Zhuang, X., Yu, Y., Liu, X., Cui, X., et al. (2013). microRNAs inhibit the translation of target mRNAs on the endoplasmic reticulum in Arabidopsis. Cell 153, 562-574. doi: 10.1016/j.cell.2013.04.005

Li, W. X., Oono, Y., Zhu, J., He, X. J., Wu, J. M., Iida, K., et al. (2008). The Arabidopsis NFYA5 transcription factor is regulated transcriptionally and posttranscriptionally to promote drought resistance. Plant Cell 20, 2238-2251. doi: $10.1105 /$ tpc. 108.059444

Li, Z., Li, B., Shen, W.-H., Huang, H., and Dong, A. (2012). TCP transcription factors interact with AS2 in the repression of class-I KNOX genes in Arabidopsis thaliana. Plant J. 71, 99-107. doi: 10.1111/j.1365-313X.2012.04973.x

Liao, W., Yang, Y., Li, Y., Wang, G., and Peng, M. (2016). Genome-wide identification of cassava R2R3 MYB family genes related to abscission zone separation after environmental-stress-induced abscission. Sci. Rep. 6:32006. doi: $10.1038 /$ srep32006

Lindemose, S., Jensen, M. K., de Velde, J. V., O’Shea, C., Heyndrickx, K. S., Workman, C. T., et al. (2014). A DNA-binding-site landscape and regulatory network analysis for NAC transcription factors in Arabidopsis thaliana. Nucleic Acids Res. 42, 7681-7693. doi: 10.1093/nar/gku502

Liu, D., Song, Y., Chen, Z., and Yu, D. (2009). Ectopic expression of miR396 suppresses GRF target gene expression and alters leaf growth in Arabidopsis. Physiol. Plant. 136, 223-236. doi: 10.1111/j.1399-3054.2009.01229.x 
Liu, J., Osbourn, A., and Ma, P. (2015). MYB transcription factors as regulators of phenylpropanoid metabolism in plants. Mol. Plant 8, 689-708. doi: 10.1016/j. molp.2015.03.012

Liu, L., Du, H., Tang, X. F., Wu, Y. M., Huang, Y. B., and Tang, Y. X. (2008). [The roles of MYB transcription factors on plant defense responses and its molecular mechanism.]. Yi Chuan 30, 1265-1271.

Liu, L., White, M. J., and MacRae, T. H. (1999). Transcription factors and their genes in higher plants functional domains, evolution and regulation. Eur. J. Biochem. 262, 247-257.

Liu, Q., and Zhang, H. (2012). Molecular identification and analysis of arsenite stress-responsive miRNAs in rice. J. Agric. Food Chem. 60, 6524-6536. doi: 10.1021/jf300724t

Liu, Z., Gu, C., Chen, F., Jiang, J., Yang, Y., Li, P., et al. (2012). Identification and expression of an APETALA2-Like gene from Nelumbo nucifera. Appl. Biochem. Biotechnol. 168, 383-391. doi: 10.1007/s12010-012-9782-9

Luo, Y., Guo, Z., and Li, L. (2013). Evolutionary conservation of microRNA regulatory programs in plant flower development. Dev. Biol. 380, 133-144. doi: 10.1016/j.ydbio.2013.05.009

Lv, D. K., Bai, X., Li, Y., Ding, X. D., Ge, Y., Cai, H., et al. (2010). Profiling of cold-stress-responsive miRNAs in rice by microarrays. Gene 459, 39-47. doi: 10.1016/j.gene.2010.03.011

Ly, L. L., Yoshida, H., and Yamaguchi, M. (2013). Nuclear transcription factor Y and its roles in cellular processes related to human disease. Am. J. Cancer Res. 3, 339-346.

Ma, J., Wang, Q., Sun, R., Xie, F., Jones, D. C., and Zhang, B. (2014). Genome-wide identification and expression analysis of TCP transcription factors in Gossypium raimondii. Sci. Rep. 4:6645. doi: 10.1038/srep06645

Ma, X., Tang, Z., Qin, J., and Meng, Y. (2015). The use of high-throughput sequencing methods for plant microRNA research. RNA Biol. 12, 709-719. doi: 10.1080/15476286.2015.1053686

Maizel, A., and Weigel, D. (2004). Temporally and spatially controlled induction of gene expression in Arabidopsis thaliana. Plant J. 38, 164-171. doi: 10.1111/j. 1365-313X.2004.02027.x

Manassero, N. G., Viola, I. L., Welchen, E., and Gonzalez, D. H. (2013). TCP transcription factors: architectures of plant form. Biomol. Concepts 4, 111-127. doi: 10.1515/bmc-2012-0051

Mao, H., Yu, L., Li, Z., Liu, H., and Han, R. (2016). Molecular evolution and gene expression differences within the HD-Zip transcription factor family of Zea mays L. Genetica 144, 243-257. doi: 10.1007/s10709-016-9896-Z

Maunoury, N., and Vaucheret, H. (2011). AGO1 and AGO2 act redundantly in miR408-mediated Plantacyanin regulation. PLOS ONE 6:e28729. doi: 10.1371/ journal.pone.0028729

May, P., Liao, W., Wu, Y., Shuai, B., Richard McCombie, W., Zhang, M. Q., et al. (2013). The effects of carbon dioxide and temperature on microRNA expression in Arabidopsis development. Nat. Commun. 4, 2145. doi: 10.1038/ncomms3145

Meng, Y., Shao, C., and Chen, M. (2011). Toward microRNA-mediated gene regulatory networks in plants. Brief. Bioinform. 12, 645-659. doi: 10.1093/bib/ bbq091

Meyer, R. C., Hönig, G., Brandt, R., Arana-Ceballos, F., Neitsch, C., Reuter, G., et al. (2015). Overexpression of Arabidopsis thaliana ERI, the homolog of C. elegans Enhancer of RNAinterference, leads to enhanced growth. Front. Plant Sci. 6:531. doi: 10.3389/fpls.2015.00531

Mitsuda, N., and Ohme-Takagi, M. (2009). Functional analysis of transcription factors in Arabidopsis. Plant Cell Physiol. 50, 1232-1248. doi: 10.1093/pcp/ pcp075

Mittler, R. (2006). Abiotic stress, the field environment and stress combination. Trends Plant Sci. 11, 15-19. doi: 10.1016/j.tplants.2005.11.002

Miyoshi, T., Ito, K., Murakami, R., and Uchiumi, T. (2016). Structural basis for the recognition of guide RNA and target DNA heteroduplex by Argonaute. Nat. Commun. 7:11846. doi: 10.1038/ncomms11846

Mlotshwa, S., Yang, Z., Kim, Y., and Chen, X. (2006). Floral patterning defects induced by Arabidopsis APETALA2 and microRNA172 expression in Nicotiana benthamiana. Plant Mol. Biol. 61, 781-793. doi: 10.1007/s11103-006-0049-0

Morris, K. V., and Mattick, J. S. (2014). The rise of regulatory RNA. Nat. Rev. Genet. 15, 423-437. doi: 10.1038/nrg3722

Mutum, R. D., Kumar, S., Balyan, S., Kansal, S., Mathur, S., and Raghuvanshi, S. (2016). Identification of novel miRNAs from drought tolerant rice variety Nagina 22. Sci. Rep. 6:30786. doi: 10.1038/srep30786
Myers, Z. A., Kumimoto, R. W., Siriwardana, C. L., Gayler, K. K., Risinger, J. R., Pezzetta, D., et al. (2016). NUCLEAR FACTOR Y, Subunit C (NFYC) transcription factors are positive regulators of photomorphogenesis in Arabidopsis thaliana. PLoS Genet. 12:e1006333. doi: 10.1371/journal.pgen. 1006333

Naeem, H., Kuffner, R., and Zimmer, R. (2011). MIRTFnet: analysis of miRNA regulated transcription factors. PLOS ONE 6:e22519. doi: 10.1371/journal.pone. 0022519

Nag, A., King, S., and Jack, T. (2009). miR319a targeting of TCP4 is critical for petal growth and development in Arabidopsis. Proc. Natl. Acad. Sci. U.S.A. 106, 22534-22539. doi: 10.1073/pnas.0908718106

Nazarov, P. V., Reinsbach, S. E., Muller, A., Nicot, N., Philippidou, D., Vallar, L., et al. (2013). Interplay of microRNAs, transcription factors and target genes: linking dynamic expression changes to function. Nucleic Acids Res. 41, 2817-2831. doi: 10.1093/nar/gks1471

Ng, D. W., Zhang, C., Miller, M., Palmer, G., Whiteley, M., Tholl, D., et al. (2011). cis- and trans-Regulation of miR163 and target genes confers natural variation of secondary metabolites in two Arabidopsis species and their allopolyploids. Plant Cell 23, 1729-1740. doi: 10.1105/tpc.111.083915

Nguyen, N. H., and Lee, H. (2016). MYB-related transcription factors function as regulators of the circadian clock and anthocyanin biosynthesis in Arabidopsis. Plant Signal. Behav. 11:e1139278. doi: 10.1080/15592324.2016. 1139278

Niemeier, S., Alves Junior, L., and Merkle, T. (2010). Improvement of the design and generation of highly specific plant knockdown lines using primary synthetic microRNAs (pri-smiRNAs). BMC Res Notes 3:59. doi: 10.1186/1756-0500-3-59

Nova-Franco, B., Íñiguez, L. P., Valdés-López, O., Alvarado-Affantranger, X., Leija, A., Fuentes, S. I., et al. (2015). The Micro-RNA172c-APETALA2-1 node as a key regulator of the common bean-Rhizobium etli Nitrogen Fixation Symbiosis. Plant Physiol. 168, 273-291. doi: 10.1104/pp.114.255547

Olsen, A. N., Ernst, H. A., Leggio, L. L., and Skriver, K. (2005). NAC transcription factors: structurally distinct, functionally diverse. Trends Plant Sci. 10, 79-87. doi: 10.1016/j.tplants.2004.12.010

Omidbakhshfard, M. A., Proost, S., Fujikura, U., and Mueller-Roeber, B. (2015). Growth-Regulating Factors (GRFs): a small transcription factor family with important functions in plant biology. Mol. Plant 8, 998-1010. doi: 10.1016/j. molp.2015.01.013

Orenstein, Y., and Shamir, R. (2016). Modeling protein-DNA binding via highthroughput in vitro technologies. Brief. Funct. Genomics doi: 10.1093/bfgp/ elw030 [Epub ahead of print].

Ori, N., Cohen, A. R., Etzioni, A., Brand, A., Yanai, O., Shleizer, S., et al. (2007). Regulation of LANCEOLATE by miR319 is required for compound-leaf development in tomato. Nat. Genet. 39, 787-791. doi: 10.1038/ng2036

Osorio, J. (2016). Gene regulation: landscape and mechanisms of transcription factor cooperativity. Nat. Rev. Genet. 17, 5. doi: 10.1038/nrg.2015.11

Ossowski, S., Schwab, R., and Weigel, D. (2008). Gene silencing in plants using artificial microRNAs and other small RNAs. Plant J. 53, 674-690. doi: 10.1111/ j.1365-313X.2007.03328.x

Padi, M., and Quackenbush, J. (2015). Integrating transcriptional and protein interaction networks to prioritize condition-specific master regulators. BMC Syst. Biol. 9, 80. doi: 10.1186/s12918-015-0228-1

Palatnik, J. F., Wollmann, H., Schommer, C., Schwab, R., Boisbouvier, J., Rodriguez, R., et al. (2007). Sequence and expression differences underlie functional specialization of Arabidopsis microRNAs miR159 and miR319. Dev. Cell 13, 115-125. doi: 10.1016/j.devcel.2007.04.012

Pandey, A., Misra, P., Bhambhani, S., Bhatia, C., and Trivedi, P. K. (2014). Expression of Arabidopsis MYB transcription factor, AtMYB111, in tobacco requires light to modulate flavonol content. Sci. Rep. 4:5018. doi: 10.1038/ srep05018

Parapunova, V., Busscher, M., Busscher-Lange, J., Lammers, M., Karlova, R., Bovy, A. G., et al. (2014). Identification, cloning and characterization of the tomato TCP transcription factor family. BMC Plant Biol. 14:157. doi: 10.1186/14712229-14- 157

Park, J. H., and Shin, C. (2014). MicroRNA-directed cleavage of targets: mechanism and experimental approaches. BMB Rep. 47, 417-423. doi: 10.5483/BMBRep. 2014.47.8.109

Payne, J. L., and Wagner, A. (2015). Mechanisms of mutational robustness in transcriptional regulation. Front. Genet. 6:322. doi: 10.3389/fgene.2015.00322 
Pecenova, L., and Farkas, R. (2016). Multiple functions and essential roles of nuclear receptor coactivators of bHLH-PAS family. Endocr. Regul. 50, 165-181. doi: 10.1515/enr-2016-0019

Pelaz, S., Ditta, G. S., Baumann, E., Wisman, E., and Yanofsky, M. F. (2000). B and C floral organ identity functions require SEPALLATA MADS-box genes. Nature 405, 200-203.

Petroni, K., Kumimoto, R. W., Gnesutta, N., Calvenzani, V., Fornari, M., Tonelli, C., et al. (2012). The Promiscuous life of plant NUCLEAR FACTOR Y transcription factors. Plant Cell 24, 4777-4792. doi: 10.1105/tpc.112.105734

Phukan, U. J., Jeena, G. S., and Shukla, R. K. (2016). WRKY transcription factors: molecular regulation and stress responses in plants. Front. Plant Sci. 7:760. doi: $10.3389 /$ fpls.2016.00760

Pireyre, M., and Burow, M. (2015). Regulation of MYB and bHLH transcription factors: a glance at the protein level. Mol. Plant 8, 378-388. doi: 10.1016/j.molp. 2014.11.022

Raffaele, S., Rivas, S., and Roby, D. (2006). An essential role for salicylic acid in AtMYB30-mediated control of the hypersensitive cell death program in Arabidopsis. FEBS Lett. 580, 3498-3504. doi: 10.1016/j.febslet.2006.05.027

Ramachandran, P., Carlsbecker, A., and Etchells, J. P. (2016). Class III HD-ZIPs govern vascular cell fate: an $\mathrm{HD}$ view on patterning and differentiation. J. Exp. Bot. 68, 55-69. doi: 10.1093/jxb/erw370

Ramachandran, V., and Chen, X. (2008). Degradation of microRNAs by a family of exoribonucleases in Arabidopsis. Science 321, 1490-1492. doi: 10.1126/science. 1163728

Ren, C., Zhang, Z., Wang, Y., Li, S., and Liang, Z. (2016). Genome-wide identification and characterization of the NF-Y gene family in grape (vitis vinifera L.). BMC Genomics 17:605. doi: 10.1186/s12864-016-2989-3

Reyes, J. L., and Chua, N.-H. (2007). ABA induction of miR159 controls transcript levels of two MYB factors during Arabidopsis seed germination. Plant J. 49, 592-606. doi: 10.1111/j.1365-313X.2006.02980.x

Rhoades, M., Reinhart, B., Lim, L., Burge, C., Bartel, B., and Bartel, D. (2002). Prediction of plant microRNA targets. Cell 110, 513-520.

Rinerson, C. I., Rabara, R. C., Tripathi, P., Shen, Q. J., and Rushton, P. J. (2015). The evolution of WRKY transcription factors. BMC Plant Biol. 15:66. doi: 10.1186/s12870-015-0456-y

Rodriguez, R. E., Ercoli, M. F., Debernardi, J. M., Breakfield, N. W., Mecchia, M. A., Sabatini, M., et al. (2015). MicroRNA miR396 regulates the switch between stem cells and transit-amplifying cells in Arabidopsis Roots. Plant Cell 27, 3354-3366. doi: 10.1105/tpc.15.00452

Rogers, K., and Chen, X. (2013). Biogenesis, turnover, and mode of action of plant MicroRNAs. Plant Cell 25, 2383-2399. doi: 10.1105/tpc.113.113159

Roy, S. (2016). Function of MYB domain transcription factors in abiotic stress and epigenetic control of stress response in plant genome. Plant Signal. Behav. 11:e1117723. doi: 10.1080/15592324.2015.1117723

Rubio-Somoza, I., and Weigel, D. (2013). Coordination of flower maturation by a regulatory circuit of three microRNAs. PLoS Genet. 9:e1003374. doi: 10.1371/ journal.pgen.1003374

Salih, H., Gong, W., He, S., Sun, G., Sun, J., and Du, X. (2016). Genomewide characterization and expression analysis of MYB transcription factors in Gossypium hirsutum. BMC Genet. 17:129. doi: 10.1186/s12863-016-0436-8

Samad, A. F. A., Ali, N. M., Ismail, I., and Murad, A. M. A. (2016). Analysis of miRNAs targeting transcription factors in Persicaria minor induced by Fusarium oxysporum. AIP Conf. Proc. 1784, 020009. doi: 10.1063/1.4966719.

Sarvepalli, K., and Nath, U. (2011). Hyper-activation of the TCP4 transcription factor in Arabidopsis thaliana accelerates multiple aspects of plant maturation. Plant J. 67, 595-607. doi: 10.1111/j.1365-313X.2011.04616.x

Sasaki, T., Suzaki, T., Soyano, T., Kojima, M., Sakakibara, H., and Kawaguchi, M. (2014). Shoot-derived cytokinins systemically regulate root nodulation. Nat. Commun. 5, 4983. doi: 10.1038/ncomms5983

Schommer, C., Bresso, E. G., Spinelli, S. V., and Palatnik, J. F. (2012). "Role of MicroRNA miR319 in plant development," in MicroRNAs in Plant Development and Stress Responses, ed. R. Sunkar (Berlin: Springer) 29-47.

Schommer, C., Palatnik, J. F., Aggarwal, P., Chetelat, A., Cubas, P., Farmer, E. E., et al. (2008). Control of jasmonate biosynthesis and senescence by miR319 targets. PLoS Biol. 6:e230. doi: 10.1371/journal.pbio.0060230

Schwab, R., Ossowski, S., Riester, M., Warthmann, N., and Weigel, D. (2006). Highly specific gene silencing by artificial microRNAs in Arabidopsis. Plant Cell 18, 1121-1133. doi: 10.1105/tpc.105.039834
Shao, C., Dong, A.-W., Ma, X., and Meng, Y. (2014). Is Argonaute 1 the only effective slicer of small RNA-mediated regulation of gene expression in plants? J. Exp. Bot. 65, 6293-6299. doi: 10.1093/jxb/eru382

Sharma, D., Tiwari, M., Pandey, A., Bhatia, C., Sharma, A., and Trivedi, P. K. (2016). MicroRNA858 is a potential regulator of phenylpropanoid pathway and plant development in Arabidopsis. Plant Physiol. 171, 944-959. doi: 10.1104/pp. 15.01831

Sharma, N., Bhalla, P. L., and Singh, M. B. (2013). Transcriptome-wide profiling and expression analysis of transcription factor families in a liverwort, Marchantia polymorpha. BMC Genomics 14:915. doi: 10.1186/1471-2164$14-915$

Shiu, S. H., Shih, M. C., and Li, W. H. (2005). Transcription factor families have much higher expansion rates in plants than in animals. Plant Physiol. 139, 18-26. doi: 10.1104/pp.105.065110

Shriram, V., Kumar, V., Devarumath, R. M., Khare, T. S., and Wani, S. H. (2016). MicroRNAs as potential targets for abiotic stress tolerance in plants. Front. Plant Sci. 7:817. doi: 10.3389/fpls.2016.00817

Shu, Y., Liu, Y., Li, W., Song, L., Zhang, J., and Guo, C. (2016). Genome-Wide Investigation of MicroRNAs and their targets in response to freezing stress in Medicago sativa L., based on high-throughput sequencing. G3 (Bethesda). 6, 755-765. doi: 10.1534/g3.115.025981

Siriwardana, C., Gnesutta, N., Kumimoto, R., Jones, D., Myers, Z., Mantovani, R., et al. (2016). NUCLEAR FACTOR Y, subunit A (NF-YA) proteins positively regulate flowering and act through FLOWERING LOCUS T. PLoS Genet. 12:e1006496. doi: 10.1371/journal.pgen.1006496

Sorin, C., Declerck, M., Christ, A., Blein, T., Ma, L., Lelandais-Briere, C., et al. (2014). A miR169 isoform regulates specific NF-YA targets and root architecture in Arabidopsis. New Phytol. 202, 1197-1211. doi: 10.1111/nph. 12735

Spanudakis, E., and Jackson, S. (2014). The role of microRNAs in the control of flowering time. J. Exp. Bot. 65, 365-380. doi: 10.1093/jxb/ert453

Suzaki, T., Yoro, E., and Kawaguchi, M. (2015). Leguminous plants: inventors of root nodules to accommodate symbiotic bacteria. Int. Rev. Cell Mol. Biol. 316, 111-158. doi: 10.1016/bs.ircmb.2015.01.004

Takahashi, R., Yamagishi, N., and Yoshikawa, N. (2013). A MYB transcription factor controls flower color in soybean. J. Hered. 104, 149-153. doi: 10.1093/ jhered/ess 081

Takeda, T., Amano, K., Ohto, M. A., Nakamura, K., Sato, S., Kato, T., et al. (2006). RNA interference of the Arabidopsis putative transcription factor TCP16 gene results in abortion of early pollen development. Plant Mol. Biol. 61, 165-177. doi: 10.1007/s11103-006-6265-9

Tang, M., Tao, Y.-B., Fu, Q., Song, Y., Niu, L., and Xu, Z.-F. (2016). An ortholog of LEAFY in Jatropha curcas regulates flowering time and floral organ development. Sci. Rep. 6:37306. doi: 10.1038/srep37306

Teotia, S., and Tang, G. (2015). To bloom or not to bloom: role of MicroRNAs in plant flowering. Mol. Plant 8, 359-377. doi: 10.1016/j.molp.2014. 12.018

Terzi, L. C., and Simpson, G. G. (2008). Regulation of flowering time by RNA processing. Curr. Top. Microbiol. Immunol. 326, 201-218.

Thomson, D. W., and Dinger, M. E. (2016). Endogenous microRNA sponges: evidence and controversy. Nat. Rev. Genet. 17, 272-283. doi: 10.1038/nrg. 2016.20

Turchi, L., Baima, S., Morelli, G., and Ruberti, I. (2015). Interplay of HD-Zip II and III transcription factors in auxin-regulated plant development. J. Exp. Bot. 66, 5043-5053. doi: 10.1093/jxb/erv174

Vashisht, I., Mishra, P., Pal, T., Chanumolu, S., Singh, T. R., and Chauhan, R. S. (2015). Mining NGS transcriptomes for miRNAs and dissecting their role in regulating growth, development, and secondary metabolites production in different organs of a medicinal herb, Picrorhiza kurroa. Planta 241, 1255-1268. doi: 10.1007/s00425-015-2255-y

Verdier, J., Zhao, J., Torres-Jerez, I., Ge, S., Liu, C., He, X., et al. (2012). MtPAR MYB transcription factor acts as an on switch for proanthocyanidin biosynthesis in Medicago truncatula. Proc. Natl. Acad. Sci. U.S.A. 109, 17661771. doi: $10.1073 /$ pnas.1120916109

Voinnet, O. (2009). Origin, biogenesis, and activity of plant microRNAs. Cell 136, 669-687. doi: 10.1016/j.cell.2009.01.046

Vu, T. V., Choudhury, N. R., and Mukherjee, S. K. (2013). Transgenic tomato plants expressing artificial microRNAs for silencing the pre-coat and coat 
proteins of a begomovirus, Tomato leaf curl New Delhi virus, show tolerance to virus infection. Virus Res. 172, 35-45. doi: 10.1016/j.virusres.2012.12.008

Wagaba, H., Patil, B. L., Mukasa, S., Alicai, T., Fauquet, C. M., and Taylor, N. J. (2016). Artificial microRNA-derived resistance to Cassava brown streak disease. J. Virol. Methods 231, 38-43. doi: 10.1016/j.jviromet.2016.02.004

Wang, B., Geng, S., Wang, D., Feng, N., Zhang, D., Wu, L., et al. (2015). Characterization of squamosa promoter binding protein-LIKE genes in wheat. J. Plant Biol. 58, 220-229. doi: 10.1007/s12374-015-0105-x

Wang, H., Avci, U., Nakashima, J., Hahn, M. G., Chen, F., and Dixon, R. A. (2010). Mutation of WRKY transcription factors initiates pith secondary wall formation and increases stem biomass in dicotyledonous plants. Proc. Natl. Acad. Sci. U.S.A. 107, 22338-22343. doi: 10.1073/pnas.1016436107

Wang, H., Li, G. B., Zhang, D. Y., Lin, J., Sheng, B. L., Han, J. L., et al. (2013). [Biological functions of HD-Zip transcription factors]. Yi Chuan 35, 1179-1188.

Wang, H., Wang, H., Shao, H., and Tang, X. (2016). Recent advances in utilizing transcription factors to improve plant abiotic stress tolerance by transgenic technology. Front. Plant Sci. 7:67. doi: 10.3389/fpls.2016.00067

Wang, Q., Liu, N., Yang, X., Tu, L., and Zhang, X. (2016). Small RNA-mediated responses to low- and high-temperature stresses in cotton. Sci. Rep. 6:35558. doi: $10.1038 /$ srep35558

Wang, Y., Lan, Q., Zhao, X., Xu, W., Li, F., Wang, Q., et al. (2016). Comparative profiling of microRNA expression in soybean seeds from genetically modified plants and their near-isogenic parental lines. PLoS ONE 11:e0155896. doi: 10. 1371/journal.pone.0155896

Welchen, E., García, L., Mansilla, N., and Gonzalez, D. H. (2013). Coordination of plant mitochondrial biogenesis: keeping pace with cellular requirements. Front. Plant Sci. 4:551. doi: 10.3389/fpls.2013.00551

Weng, L., Bai, X., Zhao, F., Li, R., and Xiao, H. (2016). Manipulation of flowering time and branching by overexpression of the tomato transcription factor SIZFP2. Plant Biotechnol. J. 14, 2310-2321. doi: 10.1111/pbi.12584

Wickramasinghe, V. O., Andrews, R., Ellis, P., Langford, C., Gurdon, J. B., Stewart, M., et al. (2014). Selective nuclear export of specific classes of mRNA from mammalian nuclei is promoted by GANP. Nucleic Acids Res. 42, 50595071. doi: 10.1093/nar/gku095

Wickramasinghe, V. O., and Laskey, R. A. (2015). Control of mammalian gene expression by selective mRNA export. Nat. Rev. Mol. Cell Biol. 16, 431-442. doi: $10.1038 / \mathrm{nrm} 4010$

Wollmann, H., Mica, E., Todesco, M., Long, J. A., and Weigel, D. (2010). On reconciling the interactions between APETALA2, miR172 and AGAMOUS with the ABC model of flower development. Development 137, 3633-3642. doi: $10.1242 /$ dev.036673

Wong, D. C. J., Schlechter, R., Vannozzi, A., Höll, J., Hmmam, I., Bogs, J., et al. (2016). A systems-oriented analysis of the grapevine R2R3-MYB transcription factor family uncovers new insights into the regulation of stilbene accumulation. DNA Res. doi: 10.1093/dnares/dsw028 [Epub ahead of print].

Wu, G., Park, M. Y., Conway, S. R., Wang, J.-W., Weigel, D., and Poethig, R. S. (2009). The sequential action of miR156 and miR172 regulates developmental timing in Arabidopsis. Cell 138, 750-759. doi: 10.1016/j.cell.2009.06.031

Wu, X., Ding, D., Shi, C., Xue, Y., Zhang, Z., Tang, G., et al. (2016). microRNAdependent gene regulatory networks in maize leaf senescence. BMC Plant Biol. 16:73. doi: 10.1186/s12870-016-0755-y

Xie, F., Wang, Q., Sun, R., and Zhang, B. (2014). Deep sequencing reveals important roles of microRNAs in response to drought and salinity stress in cotton. J. Exp. Bot. 66, 789-804. doi: 10.1093/jxb/eru437

Xie, K., Wu, C., and Xiong, L. (2006). Genomic organization, differential expression, and interaction of SQUAMOSA promoter-binding-like transcription factors and microRNA156 in rice. Plant Physiol. 142, 280-293. doi: 10.1104/pp.106.084475

Xie, Q., Frugis, G., Colgan, D., and Chua, N. H. (2000). Arabidopsis NAC1 transduces auxin signal downstream of TIR1 to promote lateral root development. Genes Dev. 14, 3024-3036.

Xie, W., Huang, J., Liu, Y., Rao, J., Luo, D., and He, M. (2015). Exploring potential new floral organ morphogenesis genes of Arabidopsis thaliana using systems biology approach. Front. Plant Sci. 6:829. doi: 10.3389/fpls.2015. 00829

Yamaguchi, A., and Abe, M. (2012). Regulation of reproductive development by non-coding RNA in Arabidopsis: to flower or not to flower. J. Plant Res. 125, 693-704. doi: 10.1007/s10265-012-0513-7
Yamaguchi, A., Wu, M. F., Yang, L., Wu, G., Poethig, R. S., and Wagner, D. (2009). The microRNA-regulated SBP-Box transcription factor SPL3 is a direct upstream activator of LEAFY, FRUITFULL, and APETALA1. Dev. Cell 17, 268-278. doi: 10.1016/j.devcel.2009.06.007

Yamaguchi, N., Jeong, C. W., Nole-Wilson, S., Krizek, B. A., and Wagner, D. (2016). AINTEGUMENTA and AINTEGUMENTA-LIKE6/PLETHORA3 Induce LEAFY expression in response to auxin to promote the onset of flower formation in Arabidopsis. Plant Physiol. 170, 283-293. doi: 10.1104/pp.15.00969

Yamasaki, K., Kigawa, T., Inoue, M., Tateno, M., Yamasaki, T., Yabuki, T., et al. (2004). A novel zinc-binding motif revealed by solution structures of DNA-binding domains of Arabidopsis SBP-family transcription factors. J. Mol. Biol. 337, 49-63. doi: 10.1016/j.jmb.2004. 01.015

Yan, X., Dong, C., Yu, J., Liu, W., Jiang, C., Liu, J., et al. (2013). Transcriptome profile analysis of young floral buds of fertile and sterile plants from the self-pollinated offspring of the hybrid between novel restorer line NR1 and Nsa CMS line in Brassica napus. BMC Genomics 14:26. doi: 10.1186/14712164-14-26

Yan, Z., Hossain, M. S., Wang, J., Valdes-Lopez, O., Liang, Y., Libault, M., et al. (2013). miR172 regulates soybean nodulation. Mol. Plant Microbe Interact. 2 , 1371-1377. doi: 10.1094/mpmi-04-13-0111-r

Yang, J., Liu, X., Xu, B., Zhao, N., Yang, X., and Zhang, M. (2013). Identification of miRNAs and their targets using high-throughput sequencing and degradome analysis in cytoplasmic male-sterile and its maintainer fertile lines of Brassica juncea. BMC Genomics 14:9. doi: 10.1186/1471-2164-14-9

Yu, H., and Gerstein, M. (2006). Genomic analysis of the hierarchical structure of regulatory networks. Proc. Natl. Acad. Sci. U.S.A. 103, 14724-14731. doi: 10.1073/pnas.0508637103

Zhang, B. (2015). MicroRNA: a new target for improving plant tolerance to abiotic stress. J. Exp. Bot. 66, 1749-1761. doi: 10.1093/jxb/erv013

Zhang, K., Shi, X., Zhao, X., Ding, D., Tang, J., and Niu, J. (2015). Investigation of miR396 and growth-regulating factor regulatory network in maize grain filling. Acta Physiol. Plant. 37, 28. doi: 10.1007/s11738-0141767-6

Zhang, W., Sun, P., He, Q., Shu, F., Wang, J., and Deng, H. (2013). Fine mapping of GS2, a dominant gene for big grain rice. Crop J. 1, 160-165. doi: 10.1016/j.cj. 2013.10.003

Zhang, X., Dong, J., Liu, H., Wang, J., Qi, Y., and Liang, Z. (2016). Transcriptome sequencing in response to salicylic acid in Salvia miltiorrhiza. PLoS ONE 11:e0147849. doi: 10.1371/journal.pone.0147849

Zhang, X., Zou, Z., Zhang, J., Zhang, Y., Han, Q., Hu, T., et al. (2011). Over-expression of sly-miR156a in tomato results in multiple vegetative and reproductive trait alterations and partial phenocopy of the sft mutant. FEBS Lett. 585, 435-439. doi: 10.1016/j.febslet.2010.12.036

Zhang, Z., and Zhang, X. (2012). Argonautes compete for miR165/166 to regulate shoot apical meristem development. Curr. Opin. Plant Biol. 15, 652-658. doi: 10.1016/j.pbi.2012.05.007

Zhao, L., Kim, Y., Dinh, T. T., and Chen, X. (2007). miR172 regulates stem cell fate and defines the inner boundary of APETALA3 and PISTILLATA expression domain in Arabidopsis floral meristems. Plant J. 51, 840-849. doi: 10.1111/j. 1365-313X.2007.03181.x

Zhao, W., Li, Z., Fan, J., Hu, C., Yang, R., Qi, X., et al. (2015). Identification of jasmonic acid-associated microRNAs and characterization of the regulatory roles of the miR319/TCP4 module under root-knot nematode stress in tomato. J. Exp. Bot. 66, 4653-4667. doi: 10.1093/jxb/erv238

Zhong, R., and Ye, Z.-H. (2007). Regulation of HD-ZIP III Genes by MicroRNA 165. Plant Signal. Behav. 2, 351-353.

Zhou, C. M., and Wang, J. W. (2013). Regulation of flowering time by MicroRNAs. J. Genet. Genomics 40, 211-215. doi: 10.1016/j.jgg.2012. 12.003

Zhou, G. K., Kubo, M., Zhong, R., Demura, T., and Ye, Z. H. (2007). Overexpression of miR165 affects apical meristem formation, organ polarity establishment and vascular development in Arabidopsis. Plant Cell Physiol. 48, 391-404. doi: 10.1093/pcp/pcm008

Zhu, H., Hu, F., Wang, R., Zhou, X., Sze, S. H., Liou, L. W., et al. (2011). Arabidopsis Argonaute10 specifically sequesters miR166/165 to regulate shoot apical meristem development. Cell 145, 242-256. doi: 10.1016/j.cell.2011.03.024 
Zhu, Q. H., and Helliwell, C. A. (2011). Regulation of flowering time and floral patterning by miR172. J. Exp. Bot. 62, 487-495. doi: 10.1093/jxb/ erq295

Conflict of Interest Statement: The authors declare that the research was conducted in the absence of any commercial or financial relationships that could be construed as a potential conflict of interest.
Copyright () 2017 Samad, Sajad, Nazaruddin, Fauzi, Murad, Zainal and Ismail. This is an open-access article distributed under the terms of the Creative Commons Attribution License (CC BY). The use, distribution or reproduction in other forums is permitted, provided the original author(s) or licensor are credited and that the original publication in this journal is cited, in accordance with accepted academic practice. No use, distribution or reproduction is permitted which does not comply with these terms. 